\title{
Managing the risk of the energy performance gap in non-domestic buildings
}

\author{
David Thompson, Esfand Burman, Dejan Mumovic, Mike Davies
}

UCL Institute for Environmental Design and Engineering, Central House, 14 Upper Woburn Place, London, WC1H 0NN

\begin{abstract}
Energy use in buildings accounts for one-third of the overall global energy consumption and total building floor area continues to increase each year as new developments are constructed and delivered. If stringent climate goals are to be met, these buildings will need to consume less energy and emit less carbon. However, design intentions for energy efficient buildings are not always met in practice. This performance gap between calculated and measured energy use in buildings threatens the progress necessary to meet these energy targets.

The aim of this paper is to identify the factors that contribute to the performance gap and propose solutions for reducing the gap in practice. A quantitative and qualitative analysis of two research programmes completed in the past few years was utilized for an in-depth look at the performance of around 50 non-domestic buildings in the United Kingdom.

While no direct links were found between any one variable and the performance gap, several correlations exist between contributing factors indicating a complex, entangled web of interrelated problems. The multitude of the variables involved presents a formidable challenge in finding practical solutions. However, the results indicate that the combination of the ventilation strategy of a building and the building services control strategy during partial occupancy is a key determinant of the performance gap. A more straightforward procurement approach with clearly delineated targets and responsibilities, along with advanced and seasonal commissioning instituted at the beginning of a project and implemented after building completion can also be very effective in reducing the gap. Finally, mandatory requirements or an appropriate system of incentives for monitoring and disclosure of performance data can help identify many of the underlying issues affecting performance in-use and untangle some of the web of complex issues across the building sector.
\end{abstract}

Keywords: Performance Gap, Building Performance Evaluation, Measured Energy Consumption, Procurement Process, Building commissioning 


\section{Practical Application}

Awareness of the performance gap and knowledge of the factors contributing to its impact on the building industry is important for all stakeholders involved in the design, construction, operation and occupation of non-domestic buildings. Understanding potential solutions to mitigate these risks may help to reduce the prevalence and magnitude of the performance gap. 


\section{INTRODUCTION}

Carbon emissions and total energy use from buildings are at an all-time high and continue to rise at alarming rates according to data from the International Energy Agency. ${ }^{1}$ In 2019 building-related $\mathrm{CO}_{2}$ emissions increased to $10 \mathrm{GtCO}_{2}$, which accounts for roughly one-third of the total global energy-related $\mathrm{CO}_{2}$ emissions and surpasses record-setting levels from 2013. ${ }^{1}$

Energy use in the building and construction sector also continues to increase, accounting for $36 \%$ of global energy use, and while the energy intensity of buildings is down from previous years, the rates at which it is reducing has slowed and nearly plateaued. ${ }^{2}$ This combined with a $2.5 \%$ increase in gross floor area per year indicates that the industry is not on track with the level of action necessary to achieve the Paris Agreement and the UN's Sustainable Development Goals. ${ }^{2}$ Building floor area is increasing at a greater rate than the global population and while energy related emissions had levelled off in the years following 2013, it resumed its upward climb in $2016 .^{1}$

Efforts have been made at all phases of a building lifecycle to implement strategies to combat the rise in energy consumption. However, intentions to reduce energy use do not always result in better performing buildings. Research has shown that actual energy use of new buildings is typically between $30 \%$ and $150 \%$ more than original estimations and can be even higher than that. ${ }^{3}$

The performance gap is a complex concept that can change meaning based on the varying approaches to building design and engineering. ${ }^{4}$ There is also no consensus on the methods of measurement, nor agreement on who is responsible for closing the gap at different stages of the building lifecycle. ${ }^{5}$

While the performance gap can have several meanings to different stakeholders, this paper focuses on the performance gap as generally defined by De Wilde ${ }^{6}$ as the difference between predicted and measured energy performance of a building; also referred to as the 'energy performance gap'.

The aim of this paper is to identify and analyse technical and process risks that impede the energy performance of non-domestic buildings and identify realistic and practical solutions, which can be used to reduce the prevalence of issues that lead to performance gaps, and ultimately result in more sustainable and energy efficient buildings.

The key objectives of the study were as follows:

1) Extract energy data and key performance determinants from previous building performance evaluations to identify recurring issues throughout the building life cycle that contribute to a performance gap

2) Synthesize building performance data through a quantitative and qualitative analysis to determine opportunities and strategies for improvement

\section{BACKGROUND}


The performance gap has been researched since some of the first major studies on measuring and evaluating building performance. These studies contribute to an awareness of the performance gap and a better understanding of its underlying causes. However, despite the quantity of existing research, the energy performance gap in buildings still remains an endemic problem in the built environment.

\subsection{Causes of the performance gap}

While the meaning of the performance gap has evolved over time, most studies related to the underlying causes of this issue focus on problems occurring at three stages of the building cycle: design, construction and operation. Research across all three stages can vary in its findings due to the lack of standardization in how to define and measure the performance gap. ${ }^{7}$ It is important to note that while most existing research categorizes the performance gap issues and solutions by a chronological timeline, issues occurring at any stage can affect the overall performance of the building.

\subsubsection{Design Stage Issues}

The design stage often bears most of the blame in the performance gap since energy predictions made with incomplete information are ultimately compared to actual performance. However, it is important to distinguish the different types of design predictions that can affect the magnitude of the performance gap. Most modelling follows two formats: compliance modelling to illustrate adherence to building regulations, and performance modelling which attempts to predict the future energy use of the building.

While the ultimate goal of energy regulations is to reduce energy use in buildings, pressure to comply with these regulations may contribute to over-optimistic predictions thereby increasing the performance gap. ${ }^{8}$ Compliance modelling typically does not consider the entire picture when making energy predictions since the goal is simply to meet regulations.

For example, Part L of the UK building regulations only applies to calculation of specific, regulated energy loads, which includes: energy required for heating, cooling, ventilation, hot water, lighting and auxiliary energy use associated with fans and pumps, but does not include, inter alia: computers, servers, catering equipment, lifts or escalators. ${ }^{5,9}$ Van Dronkelaar, et al. ${ }^{10}$ represents these energy categories as shown in Figure 2.1. However, compliance modelling was never intended to be a prediction of in-use energy consumption. ${ }^{11}$

Regulations that mandate the publishing of design stage energy-use predictions along with the actual in-use measured consumption will go a long way to bridging the performance gap. ${ }^{10}$ The disclosure of energy performance data is necessary for industry-wide improvement, enabling design teams to better understand successful strategies and ineffective approaches which can be implemented (or avoided) into more efficient and accurate designs. ${ }^{12}$ 


\begin{tabular}{|c|r|r|r|}
\hline REGULATED & UNREGULATED & DETAILED USE & OTHER \\
\hline $\begin{aligned} \text { Fixed building services, heating, cooling, hot water, } \\
\text { auxiliary energy use and internal lighting }\end{aligned}$ & $\begin{array}{r}\text { Plug loads (UK), external } \\
\text { lighting, servers, security, etc. }\end{array}$ & $\begin{aligned} \text { Extra occupancy and } \\
\text { operating hours }\end{aligned}$ & $\begin{array}{r}\text { Special uses } \\
\text { and functions }\end{array}$
\end{tabular}

Figure 2.1 - Energy calculation differences between compliance and performance modelling.

Source: ${ }^{10}$

While performance modelling aims to eliminate some of the omissions of compliance modelling and present a more thorough estimation, there are still some key issues that limit its accuracy.

One common cause of discrepancies in performance modelling is miscommunication between the client and the design team. ${ }^{4,11,13}$ This also extends to a lack of initial communication and feedback from stakeholders typically involved in later building stages such as facility managers or the operations team. ${ }^{14}$

Another issue in performance modelling is the inability of the design team to accurately predict the future uses of the building, which may result in significant changes in energy demand. ${ }^{11,14-16}$ However, while some uncertainty in performance modelling should be expected, it is unlikely that this would be a sole cause of the underestimation of energy use typically seen in modelling outputs given the lack of a normal distribution pattern around the predicted values when compared against measured performance. Beyond inaccurate predictions, energy performance may be affected by poor design of buildings systems, or lack of detail from designers. ${ }^{3,4}$

\subsubsection{Construction Stage Issues}

While the design stage is often the main focus of research into the causes of the performance gap, the construction and commissioning of a building can have a significant impact on measured energy performance.

Many papers conclude that the quality of workmanship, particularly insulation and airtightness, often does not meet design specifications and contributes to poor energy and thermal performance. ${ }^{4,11,13,14,17}$ In many cases, the contractor is required to specify construction details on-the-job, which may differ from designer intentions and lead to common problems such as the creation of thermal bridges and higher air permeability. ${ }^{18}$

Complexity in the building design may also lead to issues in the buildability or proper construction sequence; especially in energy efficient designs. ${ }^{19}$ This lack of communication and feedback between the design team and contractors can also result in performance issues related to value engineering of specified materials or systems. ${ }^{18}$

Since the Latham Report identified deficiencies in the UK construction industry back in 1994, many studies have attempted to provide solutions to rectify those shortcomings. Latham himself made 53 recommendations to improve the industry, several of which would directly affect the performance gap, such as, clearly defining responsibilities in building service design, the use of coordinated project information (CPI) between designers and contractors and holding contractors and subcontractors to higher quality standards of workmanship. ${ }^{20}$ 
During the construction stage there is a period that involves commencement and commissioning of building services. If this section is rushed or implemented poorly, as it often is, building performance efficiency can be compromised. ${ }^{10}$ If the building is not commissioned properly, the operators may not be able to adequately operate and maintain complex systems or equipment to specified requirements after building handover. ${ }^{3}$

Frameworks such as Soft Landings aim to improve the commissioning process through an early implementation and extended handover, and can engage designers and contractors beyond completion to ensure buildings are performing more closely with design standards. ${ }^{21}$ It aims to provide a holistic solution that is implemented at the start of the design process and remains consequential throughout the building development. ${ }^{12}$

\subsubsection{Operation Stage Issues}

Several researchers have looked at the impact of problems that occur during operation, with one such study by Wang et al., ${ }^{22}$ finding that poor operating practices resulted in an energy increase of 49-79\% over predictions. However, the same study showed a reduction in energy consumption of $15-29 \%$ was possible due to good operating practices indicating that the quality of the building management team can have a substantial impact on performance. ${ }^{22}$

One of the main factors contributing to the performance gap is related to the varying nature of occupant behaviour. ${ }^{11,14,16,23}$ This can be partially linked back to inaccurate predictions made during building design, especially when the end user is unknown. Furthermore, the occupiers themselves are prone to misunderstand and misuse building systems, alter hours of occupancy and prioritize thermal comfort over energy efficiency. ${ }^{10,15}$

Inconsistent procedures for measuring energy use contribute to the lack of valuable feedback to the operating team. ${ }^{24}$ However, the main issue with measuring seems to be a lack of transparency and reporting, which leads to a shortage of valuable data and an incomplete picture of the performance gap. ${ }^{25}$

Zero or low carbon building system technologies have seen considerable efficiency improvements and implementation in recent years, but the complexities, and over-estimation of their performance by designers, tend to widen the gap between their calculated and actual energy consumption. ${ }^{13,25,26}$

\subsubsection{Procurement and Contractual Arrangements}

While the three building stages addressed above dissect the performance gap issue chronologically, certain procurement decisions can impact the performance gap throughout the entire building process. A disjointed and inconsistent approach to procurement has been shown to increase performance gaps. ${ }^{27}$

Procurement strategies are very project-specific and can vary based on client needs, project size and scope. There are, however, certain inherent and consistent risks in the process that can affect the ultimate building energy performance. During this process, it is important to clarify relationship management, supply risk, coordination and learning/knowledge sharing. ${ }^{28}$

While the addition of performance-based-initiatives in procurement arrangements provides accountability from designers and contractors and attempts to ensure a certain level of operational performance of a building, it comes with certain challenges. These Energy 
Performance Contracts need to objectively define energy targets and methods of calculating energy use. ${ }^{15}$ The time period for adherence to these contractual parameters also needs to be clear and concise, whilst representing the steady performance of the building. ${ }^{15}$

One such performance-based procurement strategy that was inspired by Australia's office building rating scheme, NABERS, has recently gained traction in the UK under an industryled initiative called Design for Performance (DfP) with 13 UK office developer 'pioneers' and 25 individual delivery partners. This strategy focuses on a Commitment Agreement process which necessitates a certain level of performance from developers and their contractors, measured from actual energy use data after one year of operation. ${ }^{12,29}$

At the time of this writing, the City of London is in the process of implementing a program called 'Be Seen' which would require all major development proposals to monitor and report on their actual operational energy performance in order to increase the understanding of the performance gap and identify ways of closing it. ${ }^{30}$

The extent of the current research on the performance gap indicates that it is a complex problem with several interconnected contributing factors and an equal number of potential solutions. Yet, despite the amount of existing data revealing the magnitude and causes of the performance gap, it remains an issue that impacts building energy performance and seems to be getting worse with the inclination towards more complex and bespoke buildings with highly technical systems and controls.

\section{Methodology}

In order to meet the stated aim of the paper, which is to identify technical and process risks that impede energy performance, calculated and measured energy data were extracted from the Innovate UK building performance evaluation (BPE) programme (2010-2015) and five buildings from the EPSRC instigated Total Operational Performance of Low Carbon Buildings (TOP) research project (2016-2019), which were analysed quantitatively to determine the magnitude of the performance gaps and comparison to two types of benchmarks (typical and good practice), and qualitatively to determine the underlying causes.

The Innovate UK BPE programme was chosen due to its scope and availability of building performance data and detailed analysis of and focus on issues contributing to the performance gap. It was also the most recently completed extensive BPE in the UK at the time of this writing.

Five TOP study buildings, designed concurrent with the Innovate UK BPE programme, were chosen to increase the sample of viable UK non-domestic building performance data for analysis, and also to review potential impacts of the findings of the BPE programme on design and development of new buildings. The same methods were applied to both sets of buildings for the purpose of this study.

\subsection{Innovate UK BPE Programme}

The Innovate UK BPE Programme was an ambitious, £8M initiative designed to address fundamental problems with performance gaps in the UK building industry, which resulted in a substantial amount of information on the in-use performance of multiple domestic and nondomestic buildings, of which, this paper focuses solely on the non-domestic reports. 


\subsubsection{BPE Programme Scope}

The BPE programme involved 48 projects (reports) containing 56 non-domestic buildings in a variety of sectors. Due to availability and completeness of the reports, this paper focused on 42 of the reports, which studied 49 buildings with an additional 5 buildings from the TOP study. Table 3-1 contains a summary of the scope of each study including buildings that were referenced in this paper. A summary of key building characteristics can be found in Appendix A.

The BPE study examined properties with a minimum 1-2 years of operational data and used common templates to report on the buildings' fabric and systems, energy performance and occupant satisfaction, which were submitted to Innovate UK for analysis. These documents and reports enabled the study to identify common issues and suggestions for improvement in underperforming buildings; commonalities between all projects; emphasise best practices; and share lessons learned.

Table 3-1 - Innovate UK BPE \& TOP Scope of Study

\begin{tabular}{ccccc}
\hline Programme & $\begin{array}{c}\text { Total Building Performance } \\
\text { Evaluation Reports }\end{array}$ & $\begin{array}{c}\text { Total Non-Domestic } \\
\text { Buildings Studied } \\
\text { (\# bldgs) }\end{array}$ & $\begin{array}{c}\text { Buildings } \\
\text { Referenced } \\
\text { in this Paper }\end{array}$ & $\begin{array}{c}\text { Buildings } \\
\text { with Design } \\
\text { Energy } \\
\text { Calculations }\end{array}$ \\
\hline $\begin{array}{c}\text { Innovate UK BPE } \\
\text { TOP }\end{array}$ & CIBSE TM61-64; (Burman et al., 2018) & 8 & 49 & 34 \\
\cline { 3 - 5 } & & 56 & 5 & 5 \\
\hline
\end{tabular}

*Innovate UK BPE Reports sourced from (Usable Buildings Trust, 2020)

Sources: ${ }^{5,31}$

\subsubsection{BPE Programme Structure \& Methods}

In order for each BPE project team to cover certain minimum aspects, each report followed a similar structure containing a review of building systems, energy use analysis, recommendations and wider lessons learned.

Each property contained a Building Emissions Rate (BER), which includes an estimated rate of $\mathrm{CO}_{2}$ emissions per square metre of floor area. However, this figure typically only contains regulated energy use and excludes un-regulated loads.

In addition to following a consistent report structure and including a BER, contributors were required to utilise the CIBSE TM22 spreadsheet tool to analyse the total building energy consumption figures by fuel type and evaluate specific sub-metered data for a more detailed analysis of item-by-item use. In some cases, issues with the reliability of sub-metered data affected the analysis and conclusions of specific building component energy consumption.

\subsection{TOP Research Project}

The Total Operational Performance of Low Carbon Buildings ('TOP') project was a collaborative research between UCL and Tsinghua University to evaluate operational performance of several new buildings in the UK and China in four key sectors: offices, schools, hospitals, and large residential buildings. The project's aim was to adopt a holistic approach to building performance and explore the effects of different regulatory and broader 
techno-socio-economic factors in two contrasting contexts. ${ }^{32}$ The UK component of the study informed the development of four CIBSE Technical Memoranda (TM 61-64). ${ }^{3,33-35}$ The present study used the empirical data available from the UK non-domestic buildings included in the TOP project.

\subsection{Quantitative Analysis}

In order to determine the magnitude of the performance gap and explore potential correlations, data was extracted from each of the BPE reports and 5 TOP buildings for analysis.

\subsubsection{Establishing the magnitude of the performance gap}

As a means to establish the magnitude of the performance gap, design energy must be compared with in-use consumption. Only 10 of the 49 Innovate UK BPE properties specifically listed design energy calculations in the BPE reports. There were 35 buildings that had available energy performance certificate (EPC) data, including the TOP study buildings ( 6 of which had also included design energy predictions) for a total of 39 buildings with reliable design energy data.

EPCs are based on theoretical performance of the building using default occupant density, occupancy schedules and set points; focus solely on regulated energy loads; and on their own, should not be compared directly with in-use performance. However, it is possible to extract additional design energy data and an allowance for equipment loads from an EPC by using the EPC Input document. The EPC energy estimates are based on the EPC Input which includes the calculated energy figures $(\mathrm{kWh})$ for thermal and electrical energy. Using consistent benchmarking emissions factors from CIBSE TM46, these extracts can be converted into carbon emission equivalents. The extracted EPC electrical figure includes an allowance for plug-in loads based on activity types in a building (which were necessary to estimate heating and cooling loads) and therefore can be more closely compared with in-use performance.

In-use energy consumption data was available for all 54 properties and was extracted from each individual report.

Using the extracted data from energy performance calculations and representative of all energy end-uses, as Calculated Energy, and the actual Measured Energy, the percentage error was calculated as a proxy for the magnitude of the performance gap.

\subsubsection{Establishing building performance related to industry benchmarks}

In order to establish a more complete picture of how well a building is performing in addition to its performance gap, its actual energy consumption was also compared against the CIBSE TM46 industry benchmark (representing a 'typical building') and a good practice benchmark that was relevant for each building sector.

CIBSE TM46 was selected because it was used in a majority of the BPE reports and while it may not be the best comparison for each individual sector, it does allow for consistent comparison between a majority of the BPE and TOP properties. Each benchmark was then adjusted to the heating degree days (HDD) of the local climate and time period of recorded building energy data using weather data obtained from UKCIP and Stark. ${ }^{36,37}$ Table 3-2 lists the TM46 categories that were relevant to the BPE study and TOP properties along with their 
pre-adjusted energy benchmarks in $\mathrm{kWh} / \mathrm{m}^{2}$ and $\mathrm{kgCO}_{2} / \mathrm{m}^{2}$. In order to maintain consistency with the current regulatory framework in the UK for whole-building performance assessments (Criterion 1, Approved Document Part L for England) ${ }^{9}$, greenhouse gas emissions $\left(\mathrm{CO}_{2} \mathrm{e}\right)$ are used as a proxy for the energy performance. To provide a more thorough comparison against typical and good practice energy benchmarks, Energy Use Intensity (EUI) is also evaluated as a secondary performance indicator.

Table 3-2 - Raw TM46 Benchmarks used for BPE and TOP properties

\begin{tabular}{|c|c|c|c|c|c|}
\hline \multirow[b]{2}{*}{ Category } & \multicolumn{2}{|c|}{ Energy Benchmarks } & \multicolumn{3}{|c|}{ Illustrative $\mathrm{CO}_{2}$ Benchmarks } \\
\hline & $\begin{array}{l}\text { Electricity } \\
\left(\mathrm{kWh} / \mathrm{m}^{2}\right)\end{array}$ & $\begin{array}{c}\text { Fossil-Thermal } \\
\left(\mathrm{kWh} / \mathrm{m}^{2}\right)\end{array}$ & $\begin{array}{r}\text { Electricity } \\
\left(\mathrm{kgCO}_{2} / \mathrm{m}^{2}\right)\end{array}$ & $\begin{array}{c}\text { Fossil-Thermal } \\
\left(\mathrm{kgCO}_{2} / \mathrm{m}^{2}\right)\end{array}$ & $\begin{array}{c}\text { Total } \\
\left(\mathrm{kgCO}_{2} / \mathrm{m}^{2}\right)\end{array}$ \\
\hline Clinic & 70 & 200 & 38.5 & 38 & 76.5 \\
\hline General Retail & 165 & 0 & 90.8 & 0 & 90.8 \\
\hline General Office & 95 & 120 & 52.3 & 22.8 & 75.1 \\
\hline Hospital & 90 & 420 & 49.5 & 79.8 & 129.3 \\
\hline Hotel & 105 & 330 & 57.8 & 62.7 & 120.5 \\
\hline Large Food Store & 400 & 105 & 220 & 20 & 240 \\
\hline $\begin{array}{l}\text { Schools \& Seasonal } \\
\text { Public Buildings }\end{array}$ & 40 & 150 & 22 & 28.5 & 50.5 \\
\hline Workshop & 35 & 180 & 19.3 & 34.2 & 53.5 \\
\hline
\end{tabular}

Figures are pre-adjustment for HDD. Adapted from: ${ }^{38}$

While typical benchmarks can help establish a common method for comparison, they are not without faults. Benchmarks that were established in 2008, as is the case for TM46, likely do not reflect the current energy required by components such as IT systems, or the heterogeneous nature of buildings. ${ }^{39,40}$ Therefore, performance was also compared against 'good practice' benchmarks. Due to the varying building uses, different benchmarks were selected based on the best representation of each building's specific use and output is shown in Table 3-3.

Table 3-3 - Good Practice Benchmarks Used in this Study by Property Category

\begin{tabular}{|c|c|c|c|c|c|c|}
\hline Category & \multicolumn{2}{|c|}{ Energy Benchmarks } & \multicolumn{3}{|c|}{ Illustrative $\mathrm{CO}_{2}$ Benchmarks } & Source \\
\hline Community Centres & 33 & 107 & 18 & 21 & 39 & DEC \\
\hline General Office $^{3}$ & 68 & 83 & 37 & 16 & 62 & DEC \\
\hline Library & 54 & 85 & 30 & 16 & 46 & DEC \\
\hline Primary School & 35 & 97 & 19 & 19 & 38 & DEC \\
\hline Secondary School & 42 & 97 & 23 & 19 & 42 & DEC \\
\hline Uni Residence Hall & 85 & 240 & 47 & 47 & 93 & CIBSE Guide F \\
\hline
\end{tabular}

1. Using GHG Conversion Factors consistent with CIBSE TM46 - electricity: $0.55 \mathrm{kgCO}_{2} / \mathrm{kWh}$; gas: $0.194 \mathrm{kgCO}_{2} / \mathrm{kWh}$

2. Data sourced from CIBSE Energy Benchmarking Tool

3. Central Government Office Benchmark

Sources: ${ }^{41,42}$ 
Additional potential performance determinants were also extracted from each BPE report and for TOP buildings including: the type of procurement, extent of commissioning, use of Soft Landings, BREEAM rating, ventilation strategy, heating fuel and procurement type.

\subsection{Qualitative Analysis}

Using qualitative analysis to extract themes and patterns from the Innovate UK BPE reports, may help to highlight the underlying causes of poor energy performance, or conversely, help to understand which of the multitude of variables positively impacted a well-performing building.

This paper utilized the qualitative data analysis software NVivo to analyse each of the 42 BPE reports covering 49 buildings. A combination of thematic and in-vivo coding was used to extract data from each report that was related to or had an effect on the energy performance of each building. Thematic coding is simply a method for identifying, analysing and reporting patterns within data, ${ }^{7}$ while in-vivo coding uses the authors' own words to keep the data rooted in the industry lingo and the author's intent. ${ }^{43}$ The process followed for establishing qualitative codes is shown in Table 3-4. As the authors of this paper were involved in the performance evaluation of TOP buildings and its publications, the qualitative analysis was limited to the BPE reports to eliminate the risk of confirmation bias.

Table 3-4 - Process for establishing codes for qualitative analysis

\begin{tabular}{ll}
\hline Phase & \multicolumn{1}{c}{ Description of the process } \\
\hline $\begin{array}{l}\text { 1. Literature Review } \\
\text { (open coding): }\end{array}$ & $\begin{array}{l}\text { Discovering common themes in existing research and notable issues of the } \\
\text { performance gap to generate intial list of codes. }\end{array}$ \\
$\begin{array}{ll}\text { 2. Familiarisation with } & \text { Reading through BPE reports to test structure and categorisation of codes } \\
\text { IUK BPE study: } & \text { extracted from research. }\end{array}$ \\
$\begin{array}{ll}\text { 3. Searching for themes: } & \text { Using thematic and in-vivo analysis to refine code list based on report language } \\
\text { and content. }\end{array}$ \\
$\begin{array}{ll}\text { 4. Reviewing themes } \\
\text { (axial coding): }\end{array}$ & $\begin{array}{l}\text { Checking if themes work in relation to coded extracts (Phase 1) and the entire } \\
\text { data set (Phase 3) }\end{array}$ \\
themes: & $\begin{array}{l}\text { Ongoing analysis to refine the specifics of each theme, and the overall story the } \\
\text { analysis tells, generating clear definitions and names for each theme. }\end{array}$ \\
6. Producing the report: & $\begin{array}{l}\text { Selection of vivid, compelling extract examples in BPE report text related to } \\
\text { energy performance, final analysis of selected extracts, relating back of the } \\
\text { analysis to the research question and literature. }\end{array}$
\end{tabular}

Table adapted from: ${ }^{44}$

This process led to the themes in Table 3-5 to which sections of text in the reports were extracted and attributed (coded). A brief description of the application of each code is also included. These codes were applied to sections of text in the BPE reports when there was a clear indication by the authors that it negatively impacted the energy performance or affected the energy predictions.

There are several instances when a section of text can be attributable to multiple codes. For example, the text: 'Consequently, the building was handed over without being fully commissioned, particularly the BMS, and the new owners had limited knowledge of its operation and services ${ }^{45}$ would be classified as both a 'commissioning' issue and a 'lack of expertise' issue. 
Table 3-5 - Thematic codes and their application as it relates to energy performance

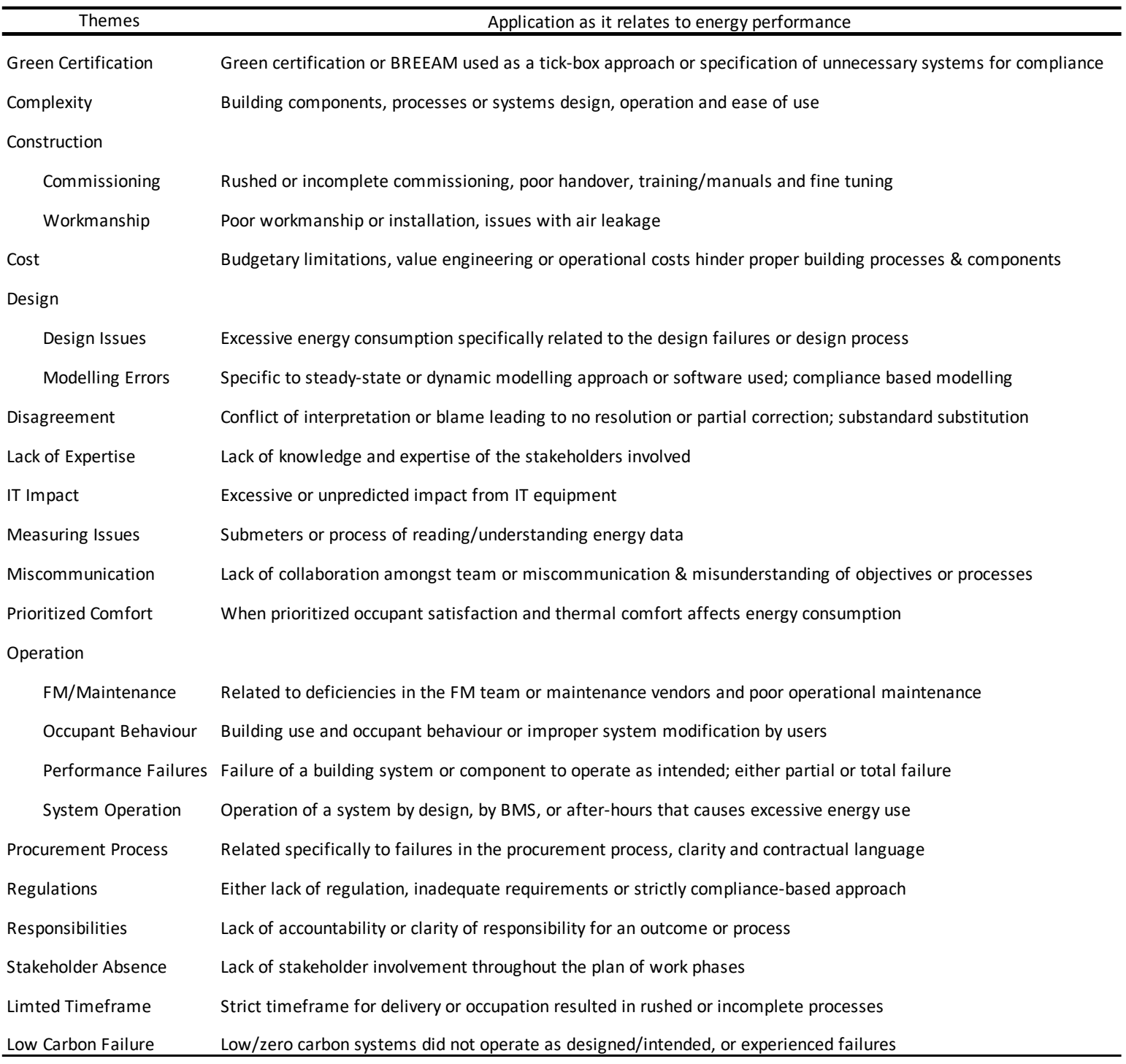

While verbatim duplications in the BPE reports were removed, multiple mentions of the same issues in different sections of the report remained in the coded extracts as separate 'mentions' to indicate the frequency and impact of a problem to the report's author(s).

\section{ReSUlts \& ANALYSIS}

As previously uncovered through multiple papers on the performance gap, good design intentions do not always translate to energy efficiencies in-use. It is therefore important to determine not only the magnitude of the deviation from these intentions but also what features or processes are habitual contributors to poor performance.

The scope of this study allows a detailed look into nearly 50 non-domestic buildings across different sectors of the UK built environment. Before determining what factors may be contributing to the performance gap, it is important to first understand the nature and magnitude of this gap. 


\subsection{Magnitude of the Performance Gap}

Comparing the measured energy to calculated energy, only 6 of the 39 buildings produced emissions below calculated values and only 2 additional buildings had errors under $5 \%$. The other 31 buildings produced between 1.1 and 5 times the calculated emissions rates.

The performance of each building compared to its calculated emissions can be seen in Figure 4.1 with a trend line slope of 1.18 (excluding one industrial property outlier with high process loads) indicating the presence of a performance gap when compared to a baseline slope of 1 , which represents calculated emissions equal to measured emissions.

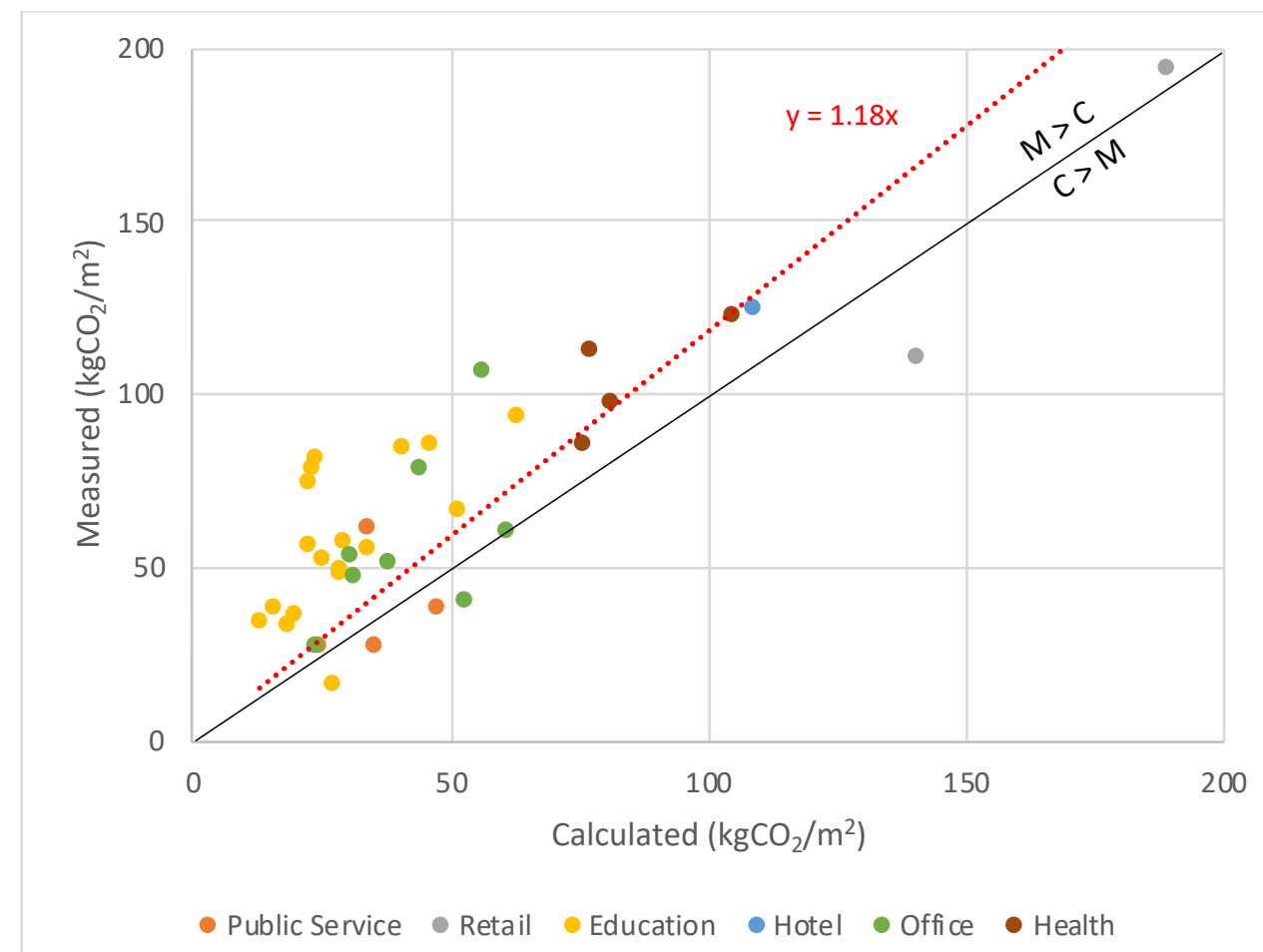

Figure 4.1 - Measured vs Calculated Emissions by Building Sector

When looking at performance compared with all 54 properties' respective TM46 benchmark, overall emissions were slightly better than the benchmarks with a $-8 \%$ difference between measured emissions and benchmark emissions. Figure 4.2 shows all properties covered in the study and how they compare with their respective TM46 benchmark. A negative percent difference indicates that a property performed better than its specific benchmark while a positive percent difference indicates worse performance.

Given that the TM46 benchmark was established in 2008 and represents the typical energy consumption over a large number of existing buildings, one could expect that the performance of new buildings, especially ones that obtain high sustainability ratings, should outperform the benchmarks. However, an average percentage difference of $-8 \%$ from the TM46 benchmark is not an indication of highly superior performance. To get a complete picture of how the BPE properties perform, it is also necessary to compare them against good practice benchmarks since these buildings, constructed around 2010, were expected to perform better than their peers. When compared with good practice benchmarks, the BPE and TOP properties performed 16\% worse overall than their respective benchmarks. Each property's comparison can be seen in Figure 4.3. 


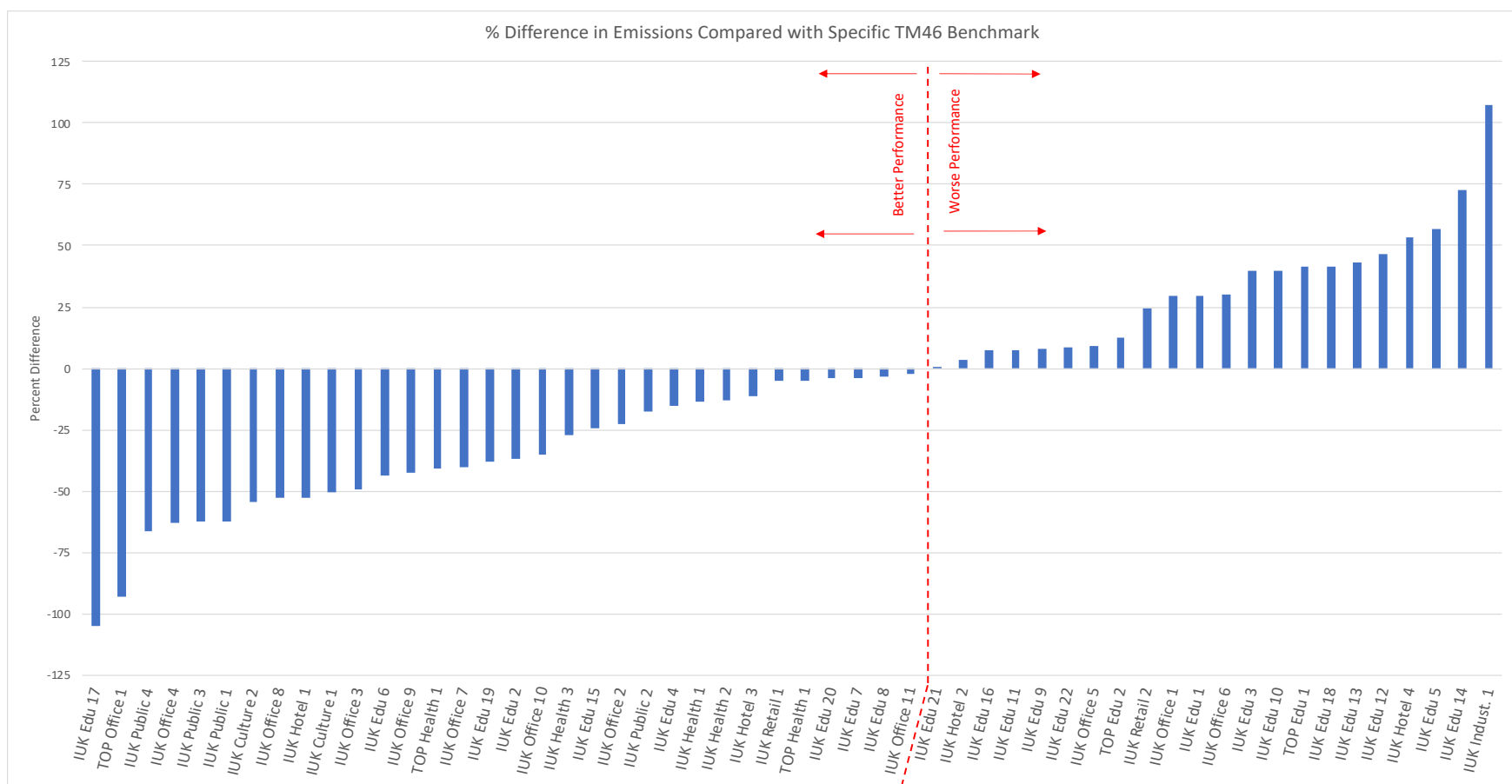

Figure 4.2 - Property Emissions Against HDD-adjusted TM46 Benchmarks

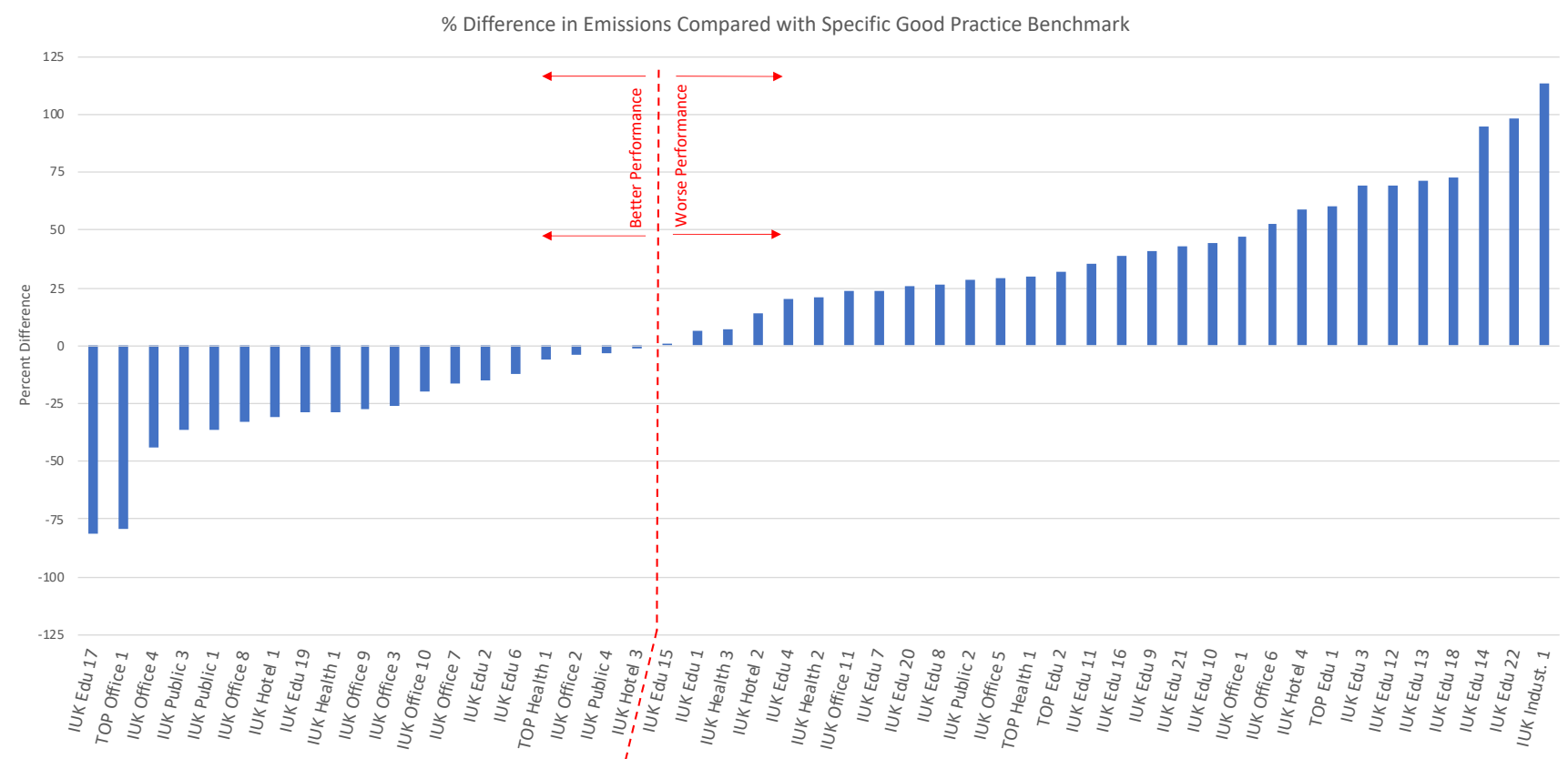

Figure 4.3 - Property Emissions Against Good Practice Benchmarks

Using carbon emissions as the only indicator of performance has some unintended consequences. It can place the focus too heavily on the use of low-carbon systems and renewable energy over the need for basic energy savings, while the alternate strategy of utilizing a combination of performance metrics can provide a more complete picture of actual performance. ${ }^{46}$ When looking at the Innovate UK BPE and TOP properties' actual energy use intensity in $\mathrm{kWh}$, their mean performance against the HDD-adjusted TM46 benchmark was $28 \%$ worse for electricity and $51 \%$ better for fossil thermal, as shown in Figure 4.4 and 
Figure 4.5 but $45 \%$ worse for electricity and $16 \%$ better for fossil thermal when comparing energy use intensity against the good practice benchmarks in Figure 4.6 and Figure 4.7.

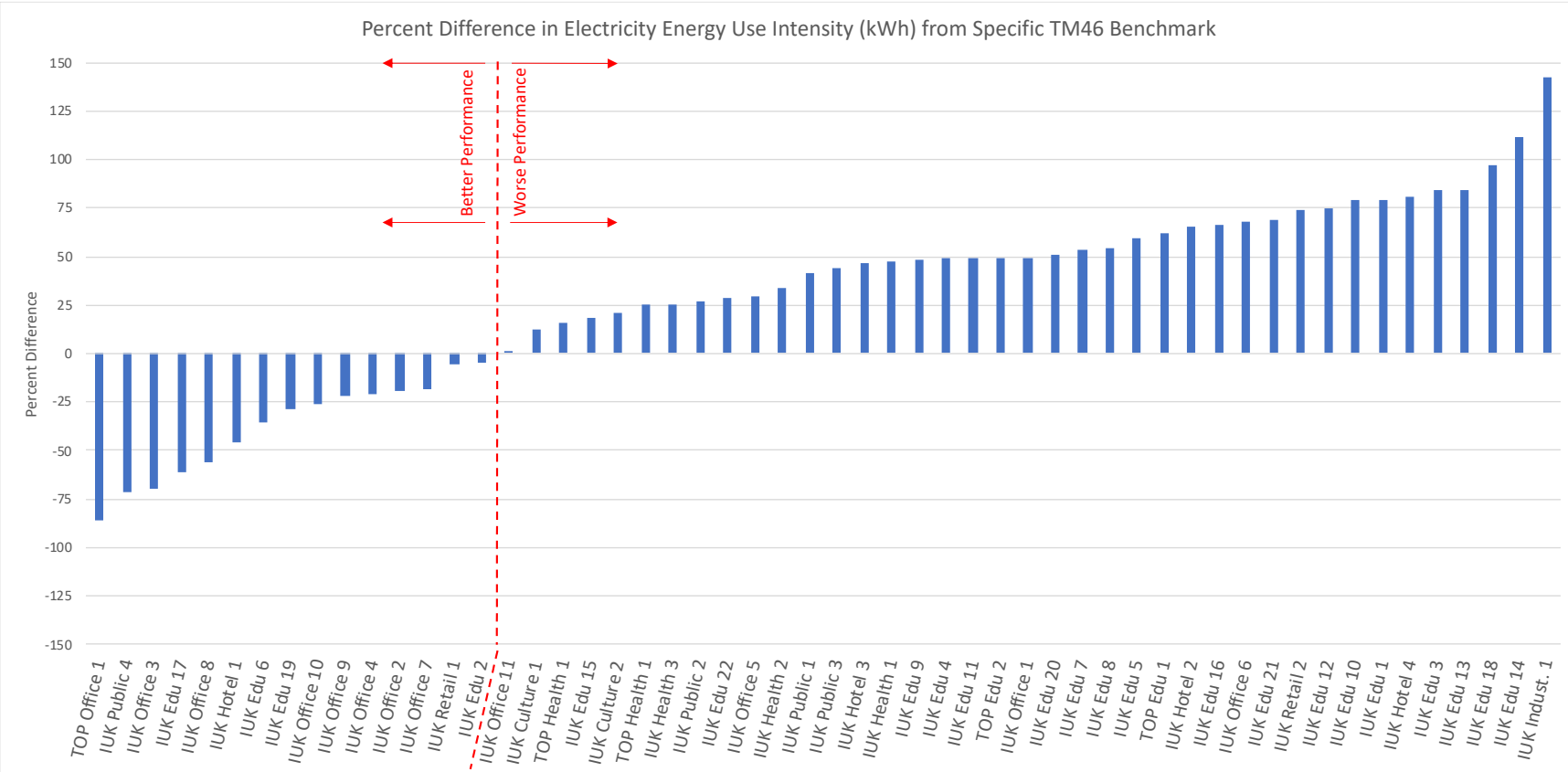

Figure 4.4 - Property Electricity Energy Use Intensity (kWh) Against HDD-adjusted TM46 Benchmarks

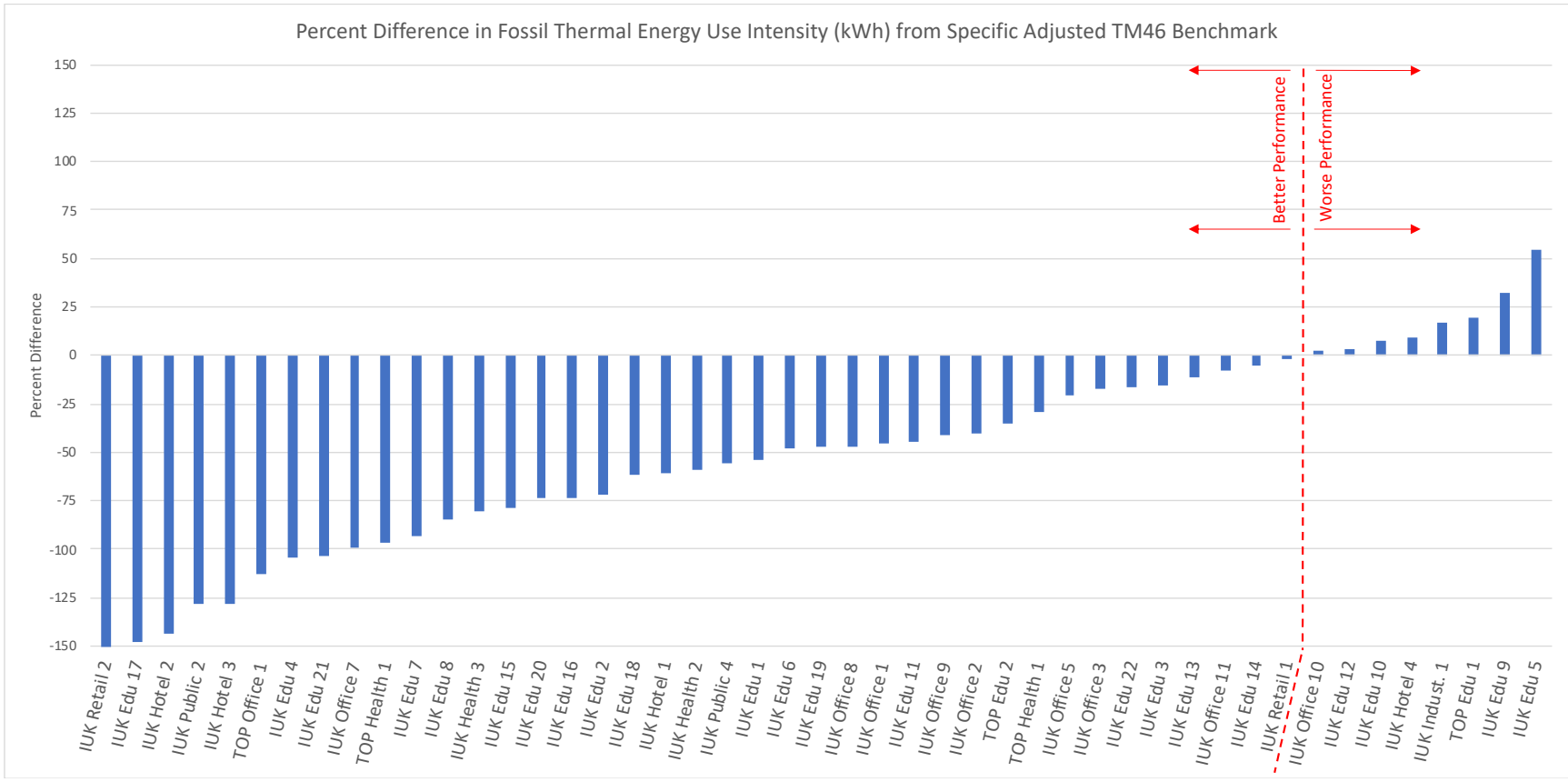

Figure 4.5 - Property Fossil Thermal Energy Use Intensity (kWh) Against HDD-adjusted TM46 Benchmarks 


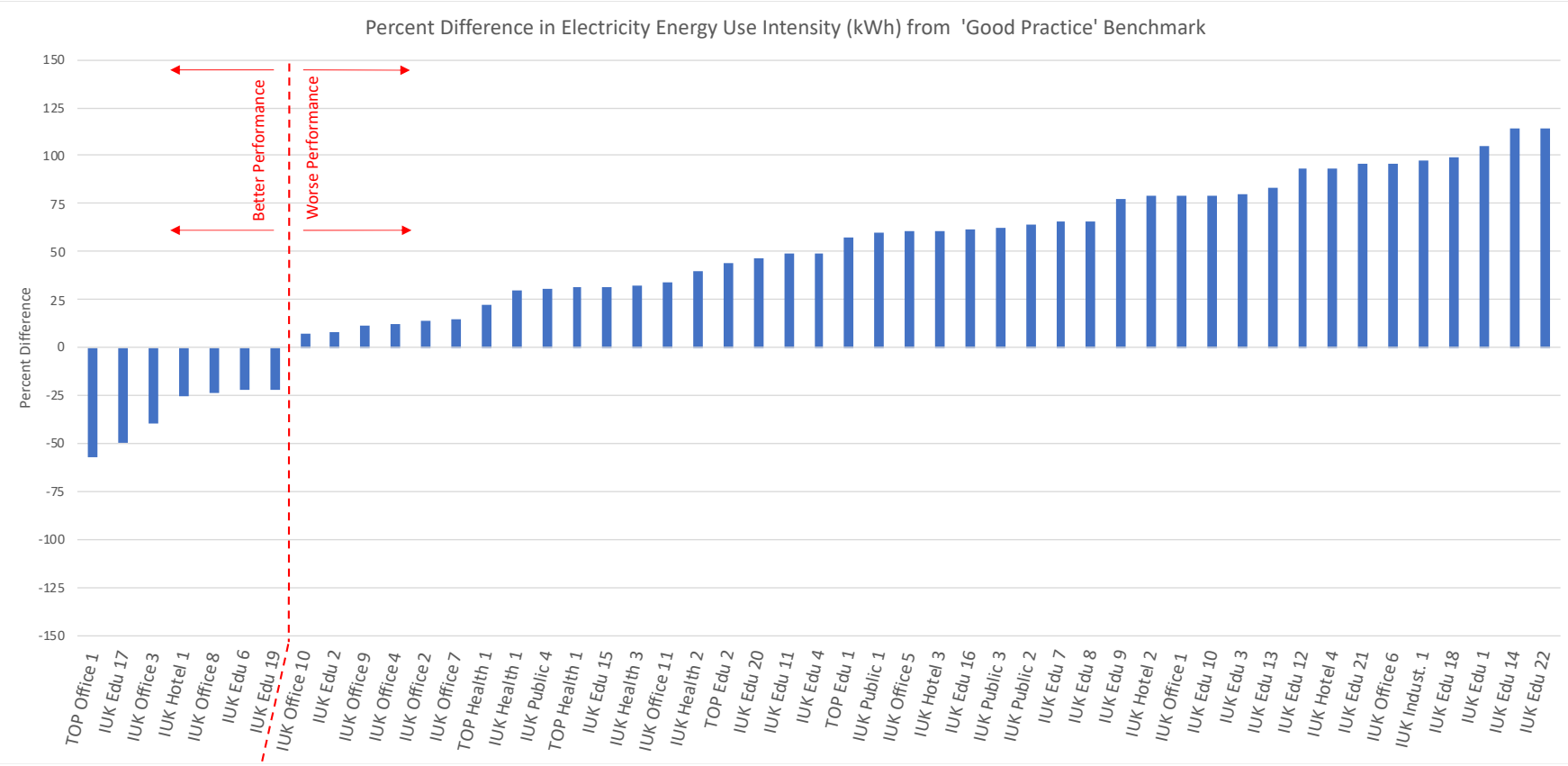

Figure 4.6 - Property Electricity Energy Use Intensity (kWh) Against Good Practice Benchmarks

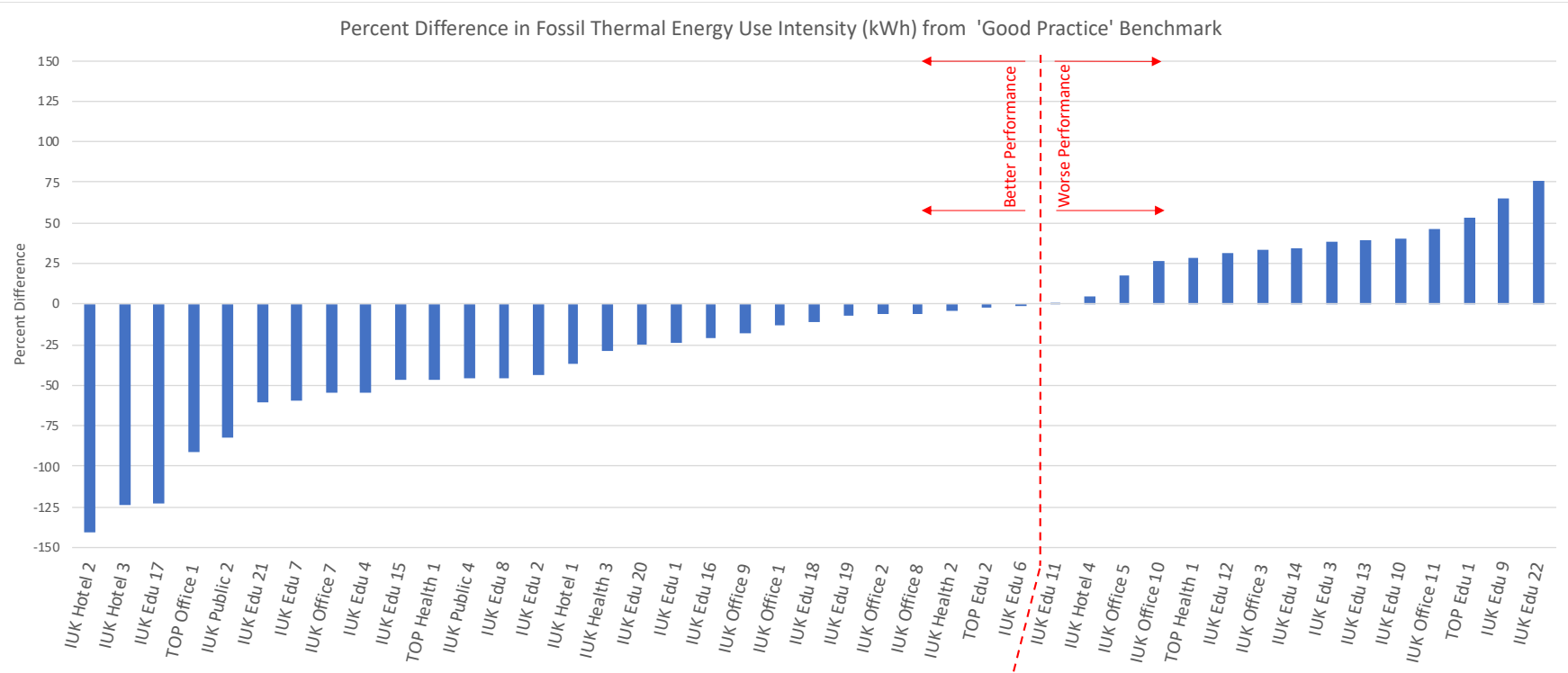

Figure 4.7 - Property Fossil Thermal Energy Use Intensity (kWh) Against Good Practice Benchmarks

\subsection{Establishing the Underlying Issues behind Performance}

Each issue that was related to energy performance in the BPE reports, was attributed to a specific theme and then quantified to determine which issues were present in each report and the frequency of their total mentions as a problem. A table showing the frequency of all coded sections in each report can be found in Appendix B.

Figure 4.8 shows that 'commissioning' was mentioned the most as an issue contributing to energy performance throughout all reports accounting for $14 \%$ of the total references. The themes 'Occupant behaviour', 'system operation' (operation of a system by design, by Building Management System, or after-hours) and 'measuring issues' (problems with metering strategies and improperly calibrated submeters) all account for approximately $10 \%$ of total mentions each. In fact, the top 5 most mentioned issues were repeated more frequently than the other 18 issues combined. 
'Commissioning' was also mentioned as an issue in the highest number of reports (95\%) as seen in Figure 4.9, indicating that, according to the report's authors, it is a contributing factor to the performance gap in almost all of the BPE projects. 'Occupant behaviour', 'Measuring Issues' and 'Design Issues' also were mentioned in more than $85 \%$ of the BPE projects.

While the number of mentions for each issue can indicate how focused the authors were on a specific problem, it does not always equate to the precise magnitude of the problem for an individual project. Same with the number of reports an issue appears in; it may just be that an issue is mentioned as a minor problem in a majority of the reports. Therefore, it is also important to consider the author's interpretation of the major issues. The BPE summary report and all but two of the individual reports mentioned a specific 'major issue' that stood out as the primary contributor to increased energy consumption. These are shown alongside the percent of reports where an issue is mentioned in Figure 4.9.

Once again, the themes 'commissioning' and 'measuring issues' are listed as major issues in the most reports, but interestingly both 'low carbon systems failure' and 'procurement process' come up as major issues despite being in the middle of the pack for overall frequency and percent of reports mentioned. This seemed to be due to the failure of biomass boilers in several of the projects and perceived issues with the design and build procurement approach.

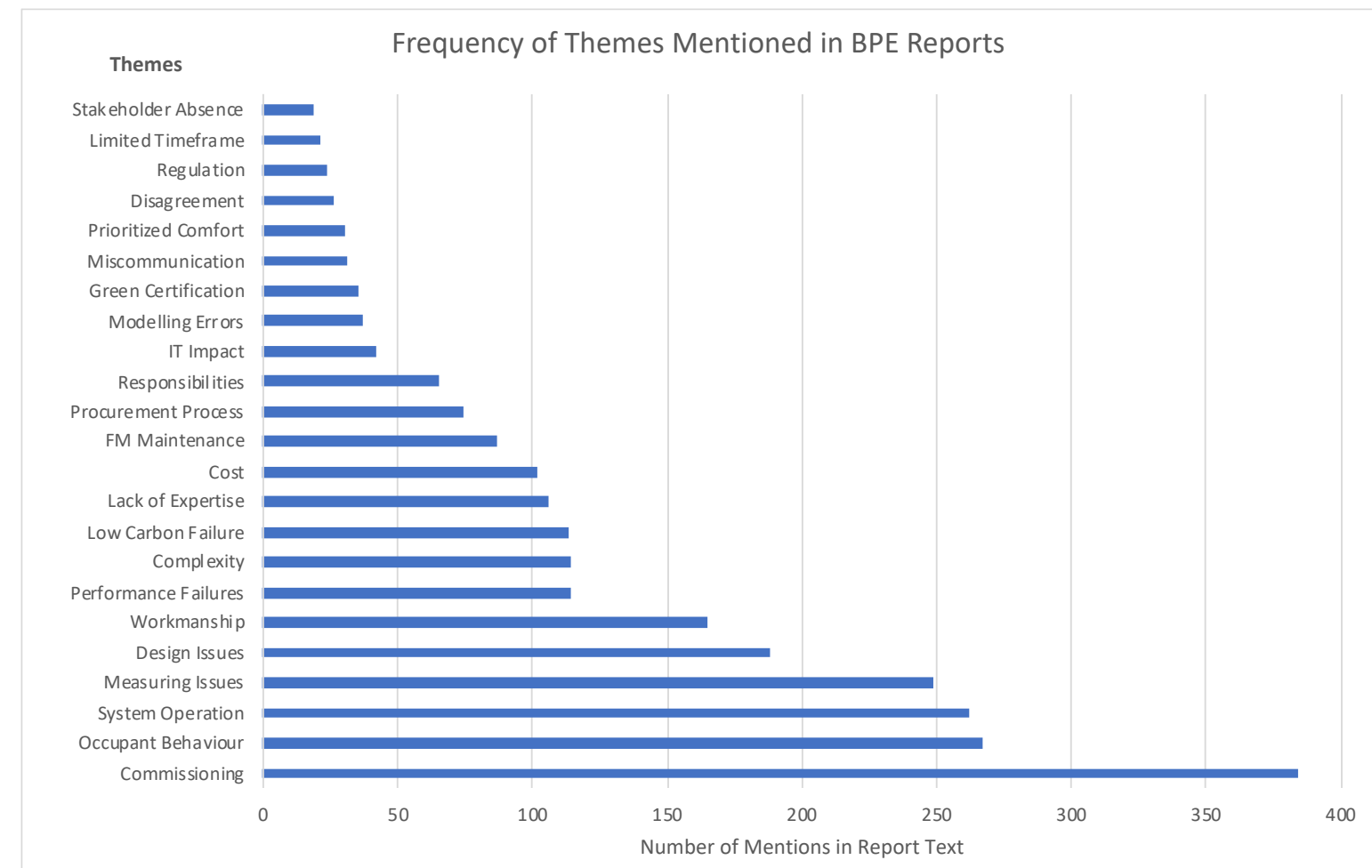

Figure 4.8 - Total Number of Mentions of Energy Performance Issues in All BPE Reports 


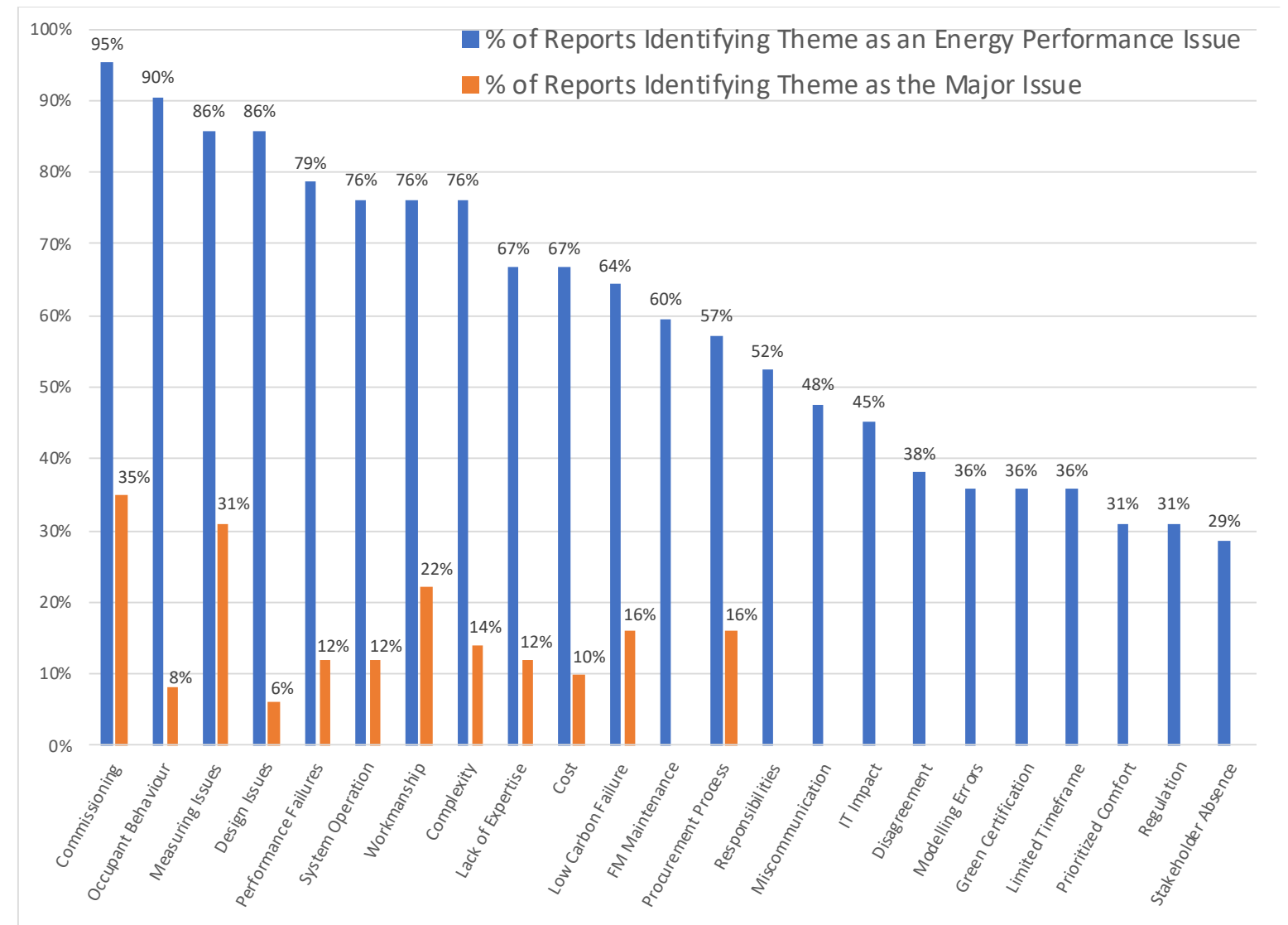

Figure 4.9 - Percent of BPE Reports Where Each Theme is Mentioned

\subsection{Exploring Underlying Issues}

After establishing the major underlying issues from the qualitative analysis, aspects about each of those issues were compared with the performance gap error percentage and the percentage difference from the TM46 and good practice benchmark using a combination of correlation, regression and T-tests.

To better visualise the interrelationships between extracted themes and also the complexity of the relationship of different issues to each other, a correlation network of all themes is shown in Figure 4.10, with the darker connecting lines indicating a stronger correlation. It is important to note that correlation between themes does not imply causation. 


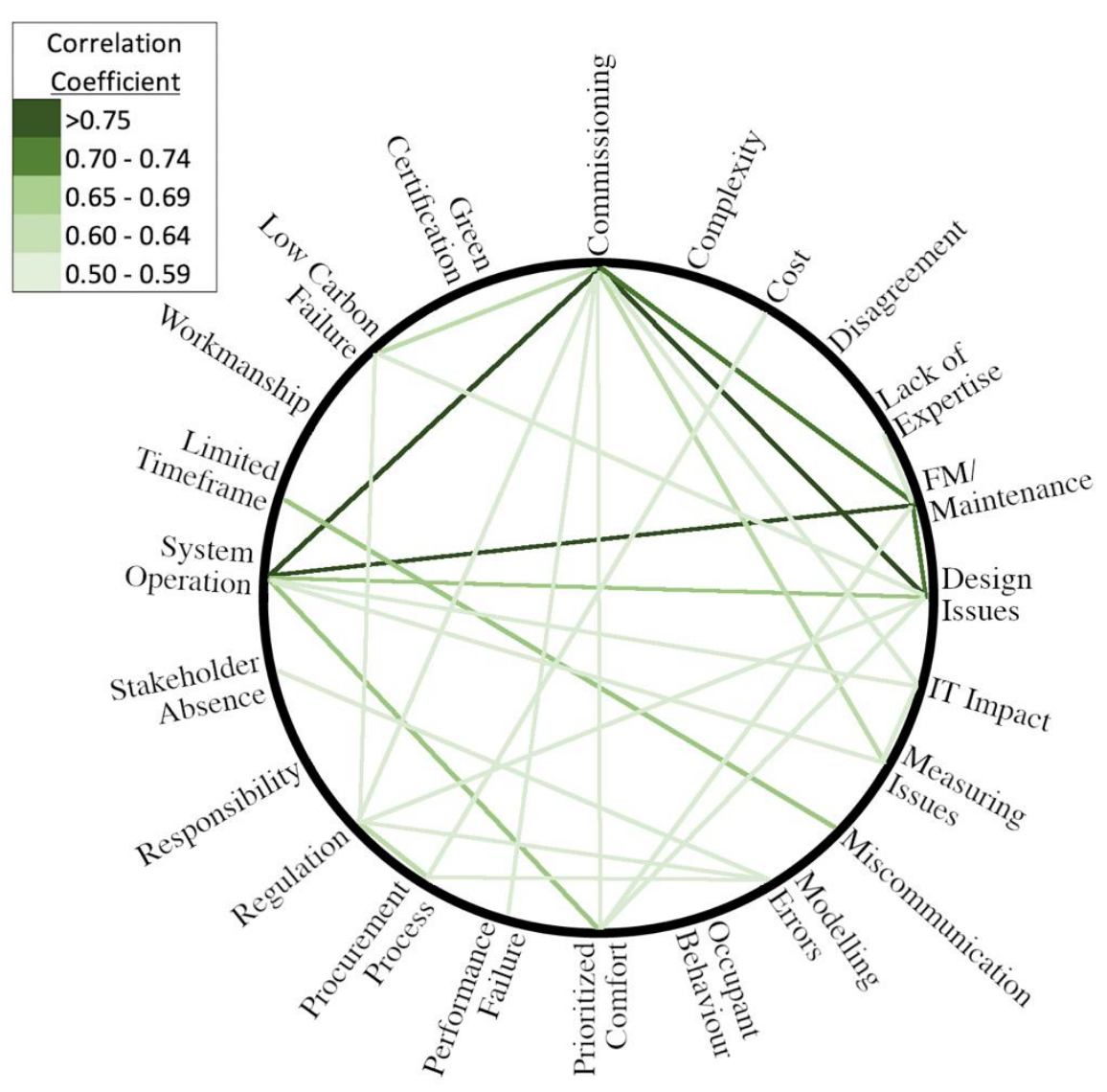

Figure 4.10 - Correlation Network of Qualitative Themes with Strength of Correlation

\subsubsection{Commissioning}

As commissioning was listed as a problem in most reports, contained the most references in the report text and was referred to as a major issue more than any other theme, it is worthwhile to analyse its potential impact on performance.

Interestingly, despite its frequent focus in the reports, commissioning issues did not show a significant correlation to either a higher performance gap or an indication of poor performance against the typical or good practice benchmark. Neither the total mentions of commissioning in the reports nor the labelling of commissioning as a 'major issue' were correlated with the performance gap or the benchmarked performance of a property.

There was also no significant difference (to a confidence level of $95 \%$ or greater) between the mean performance gap error or mean percentage difference from the benchmarks when comparing the reports with above or below average total mentions of commissioning issues (average mentions of commissioning issues were 8.4 per report). The same was true when comparing the reports that listed commissioning as a major issue from those that didn't.

A regression analysis (Figure 4.11), did show a slight difference between the performance gap of buildings where commissioning was listed as a major issue (larger gap) and those where it was not (smaller gap), however, given the small sample of reports that listed commissioning as a major issue, this may not be indicative of a causal relationship. 


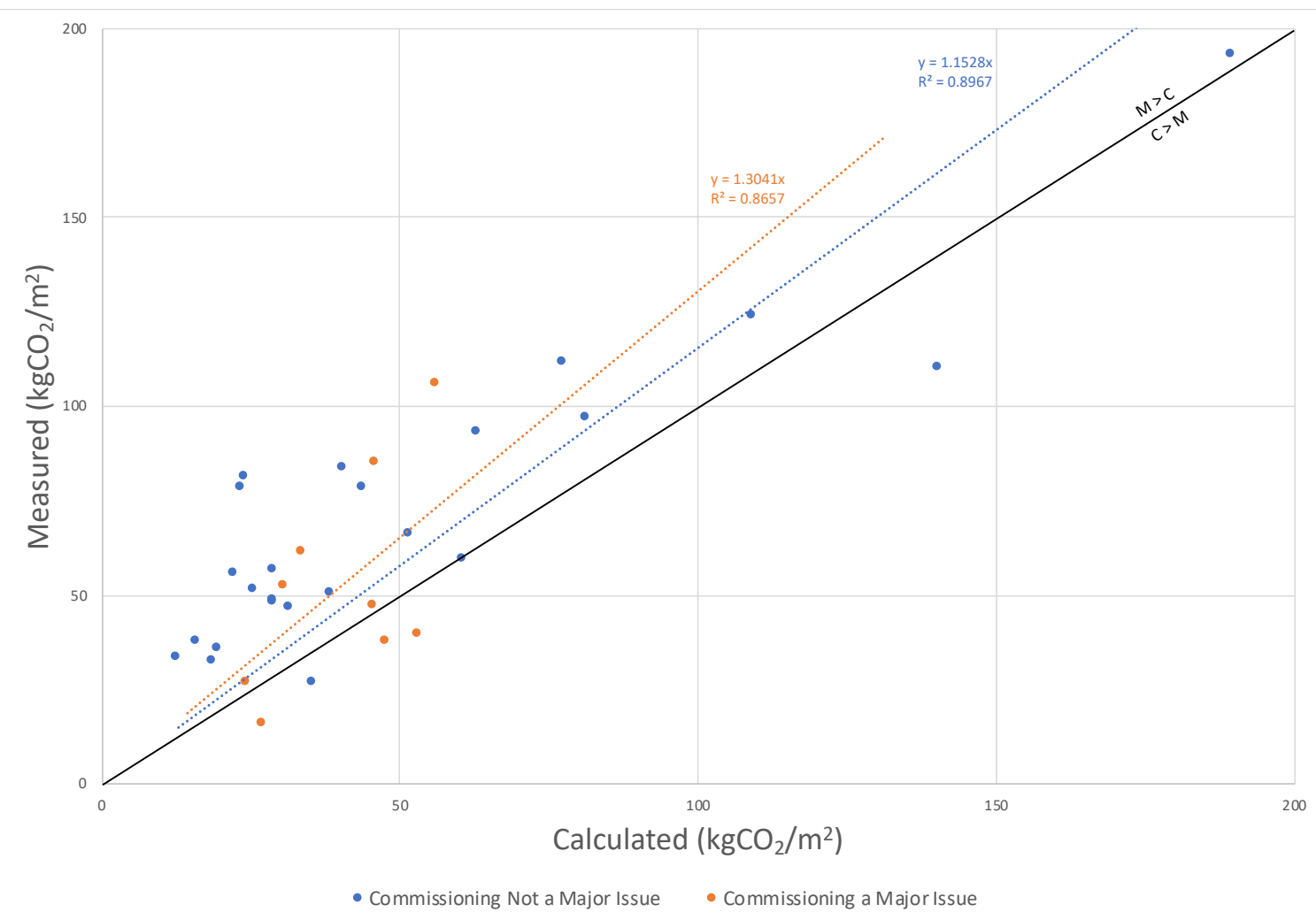

Figure 4.11 - Linear Regression Comparing Performance Gaps Where Commissioning is or is not a Major Issue

Similar results occurred when looking at whether a project used Soft Landings (or some combination of its steps). There does not appear to be a significant correlation between the magnitude of the performance gap error or the percentage difference from the benchmark and the use of Soft Landings in this study. While the mean percentage difference from the typical benchmark is lower in those projects that used Soft Landings, a T-test indicates that there is an $81 \%$ confidence level and, while impactful, does not constitute a statistically significant difference from those buildings that did not use Soft Landings without the corroboration of further empirical evidence.

While there were no identified, direct correlations between commissioning and energy performance, there were multiple correlations between commissioning and other themes as seen in Table 4-1 and above in Figure 4.10.

As expected, if there are indications of issues with commissioning, one would also anticipate an increase in issues with the operation, maintenance and performance failures of building systems as reinforced in the Innovate UK BPE reports with examples ranging from: inadequate commissioning of hydraulic isolation of thermal zones, actual specific fan power misaligned with design values, and issues with automated lighting control. ${ }^{31}$ These details are often not well defined in the commissioning plan and subtleties required to achieve energy efficiency objectives can often not be entirely addressed during the basic commissioning process as a result of the time and resource pressure experienced at the latter stages of a project and before the handover. ${ }^{47}$

Likewise, an increase in reported issues with submetering was positively correlated with commissioning as it is generally the commissioning stage when these meters are calibrated and verified. It is notable that issues with the design process are also correlated with 
commissioning issues which may point to a designer's level of contractual involvement in the commissioning process. However, it would be difficult to extrapolate that conclusion without further research into the specifics of each project.

It should also be noted that the evidence presented in the reports point to several potential root causes for commissioning issues. It would be helpful to distinguish these causes and devise appropriate strategies to address each cause: 1) issues related to design faults that compromise commissioning, 2) poor commissioning due to time constraints, and 3) shortcomings in the skillset required for effective commissioning.

Table 4-1 - Correlations between Commissioning Issues and Other Themes

\begin{tabular}{l|l}
\multicolumn{2}{l}{ Theme: } \\
\hline System Operation & 0.79 \\
Design Issues & 0.76 \\
FM Maintenance & 0.71 \\
\hline Measuring Issues & 0.63 \\
Low Carbon Failures & 0.61 \\
\hline Prioritized Comfort & 0.59 \\
IT Impact & 0.58 \\
Performance Failures & 0.57 \\
Regulation & 0.56
\end{tabular}

\begin{tabular}{|l|}
\hline $\begin{array}{l}\text { Correlation } \\
\text { Coefficient }\end{array}$ \\
\hline$>0.75$ \\
$0.70-0.74$ \\
$0.65-0.69$ \\
$0.60-0.64$ \\
$0.50-0.59$ \\
\hline
\end{tabular}

\subsubsection{Procurement}

Problems surrounding the procurement process were mentioned as a major issue in $16 \%$ of the BPE studies and when including sub-themes that are directly related to procurement such as the specific impact of a chosen procurement route, and setting contractual 'responsibilities', it becomes tied for the second most mentioned issue amongst reports.

However, similar to commissioning issues, while a major focus of the BPE reports, procurement issues themselves did not directly correlate with the magnitude of the performance gap or the performance against the benchmark. Also, there was no statistically significant difference between the mean performance of properties that listed procurement as a major issue and those that did not.

When looking specifically at the type of procurement, either traditional or design and build, there is a slight tendency for design and build to have a higher performance gap as shown in Figure 4.12 , but given the sample size and lower $\mathrm{R}^{2}$-value of the traditional procurement trend line, additional research is needed if a conclusion is to be made about whether the type of procurement directly impacts performance.

While the type of procurement may not directly affect energy performance, there were several comments from the individual BPE reports related to perceived issues with the design \& build approach specifically. These D\&B-related comments centred around a client's ability to keep track of progress, interaction with the architect (when novated to a contractor), lack of incentives for quality workmanship, ability to implement innovative techniques and adequately addressing the cost of operations and maintenance. Some of these issues are not unique to D\&B procurement and their impact on overall performance is difficult to quantify as they can affect other aspects of the building process such as quality of modelling or commissioning as well as indirectly affect systems operation and component failures. 


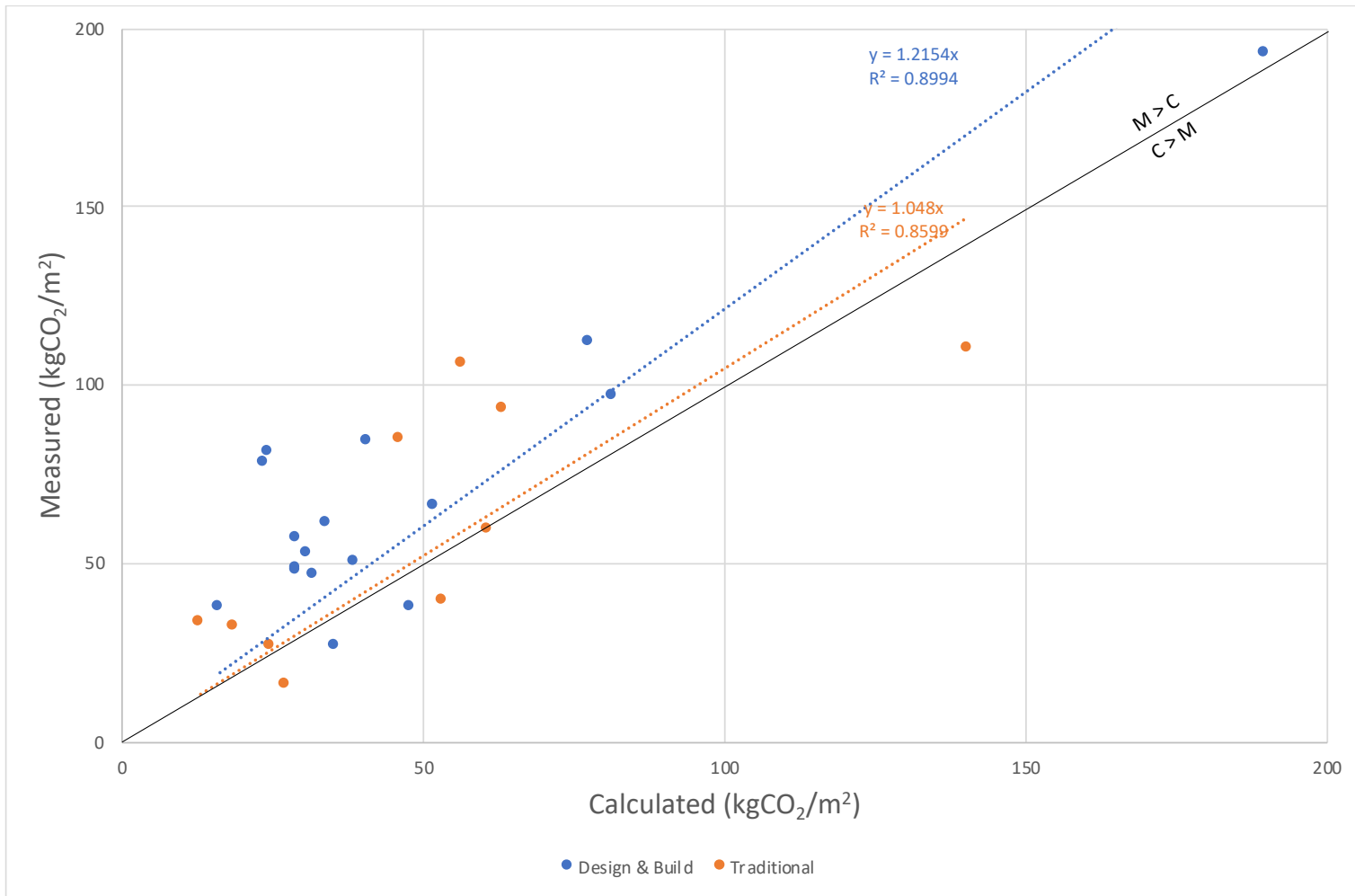

Figure 4.12 - Linear Regression comparing performance gaps of Design \& Build vs Traditional Procurements

\subsubsection{Measuring Performance}

As found in the existing literature, issues surrounding measurement of energy performance tend to be related to a lack of a consistent measuring approach and failure of the industry to openly disclose performance results for comparison and accountability, more than their direct impact on performance. This can be difficult to quantify and link directly with any performance metrics.

The process of sub-metering was recognized in the BPE reports as a substantial issue in onethird of all reports and contained the third most mentions of all issues with recurring comments on the lack of meter calibration, incorrect connections to BMS and failure of operations teams to collect or utilize the measured data.

None of these issues resulted in any direct correlation with the performance gap or the benchmarked performance. There was no significant correlation between the frequency of measurement-issue mentions and performance and there was no significant difference between the mean performance of properties that listed measurement as a major issue and those that did not.

However, based on comments extracted from the BPE reports, issues with submeters can result in delayed recognition of problems, or 'hidden issues', often with simple solutions that when unchecked, can cause an unnecessary increase in energy consumption. Often when measuring was mentioned as an issue, it was related to poor commissioning which reinforces the correlation between the two themes seen earlier in Table 4-1. Provision of submeters in new buildings, to facilitate energy use disaggregation and benchmarking, is driven by the Building Regulations. However, there is overwhelming evidence that points to major shortcomings in commissioning of these meters. It is therefore necessary to improve the commissioning process to address this issue. 


\subsubsection{Ventilation Strategy}

When comparing the chosen ventilation strategy there is no discernible difference between performance gaps of naturally ventilated buildings versus those that use mechanical ventilation as seen in Figure 4.13. However, when comparing mean performance against typical and good practice benchmarks, a T-Test indicates that naturally ventilated buildings perform better against their benchmarks than mechanically ventilated ones with a $99 \%$ confidence level and with a mean performance difference of $-22 \%$ against typical and $2 \%$ against good practice for naturally ventilated buildings.

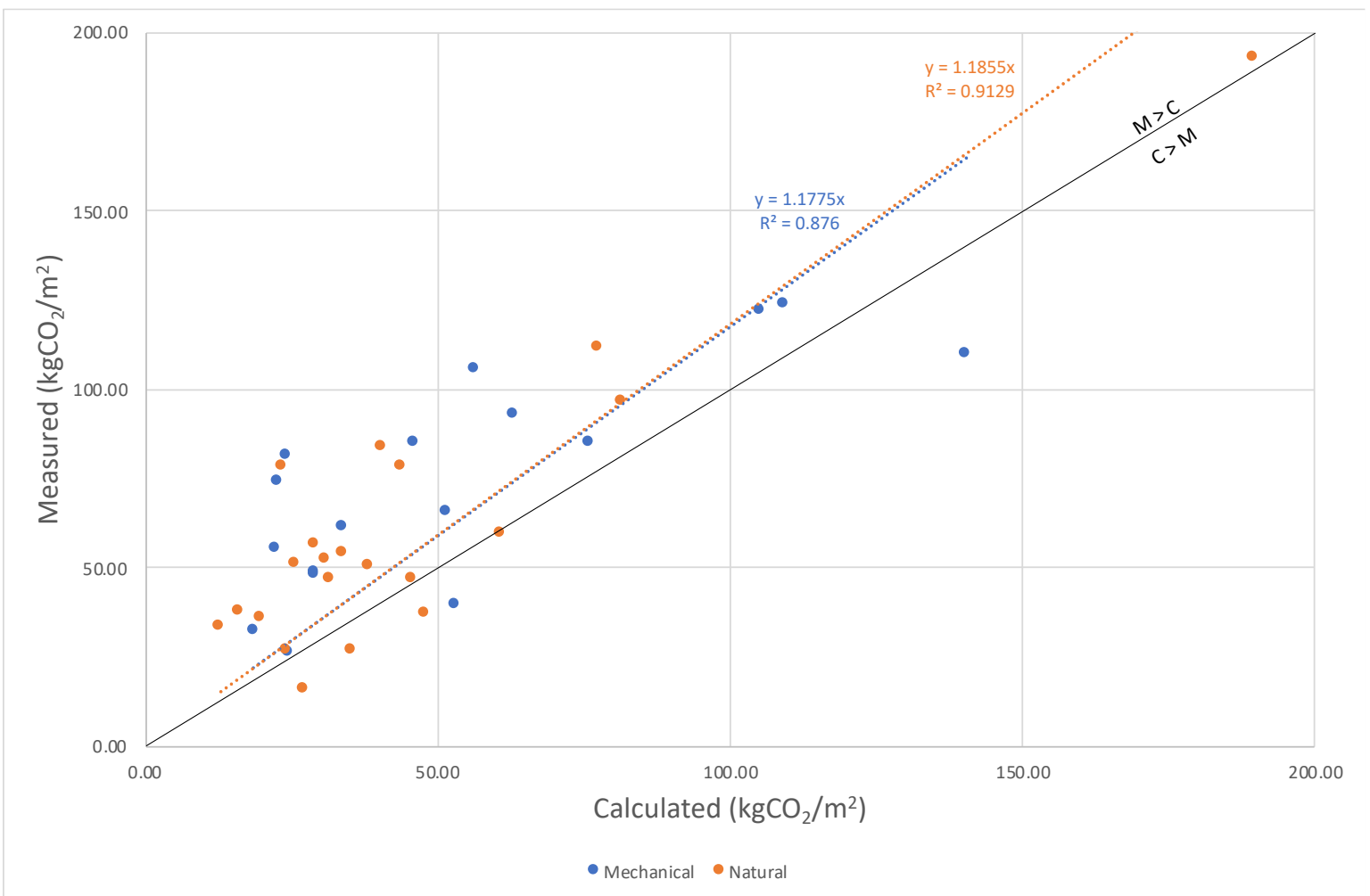

Figure 4.13 - Linear Regression comparing performance gaps of Natural vs Mechanical Ventilation

\subsubsection{Seasonality}

Previous studies identified the high risk of an energy performance gap in buildings with seasonal operation such as schools where poor control of building services, insufficient attention to HVAC zoning, and operational schedules defaulting to ON may lead to significant increase in energy consumption during out-of-hours, extra-curricular activities, half-term and summer school breaks. Optimum space-time utilisation is essential to reduce the risk of energy performance gaps in these buildings. ${ }^{47}$

Another factor that is a key driver for operational performance in schools is the increasing use of ICT equipment (desktop computers, laptops, electrically powered teaching aids, etc.). This is not fully captured at design stage and also in the building regulations and EPC calculations. These loads are considered 'non-regulated' and the regulatory building calculations only consider a default equipment load to estimate heating and cooling demand, without considering the actual electrical demand of ICT equipment.

Figure 4.14 shows a clear discrepancy in the extent of the performance gap between seasonally operated schools and other types of non-domestic buildings in the sample while Figure 4.15 looks specifically at the difference between calculated and measured emissions at each school building. 


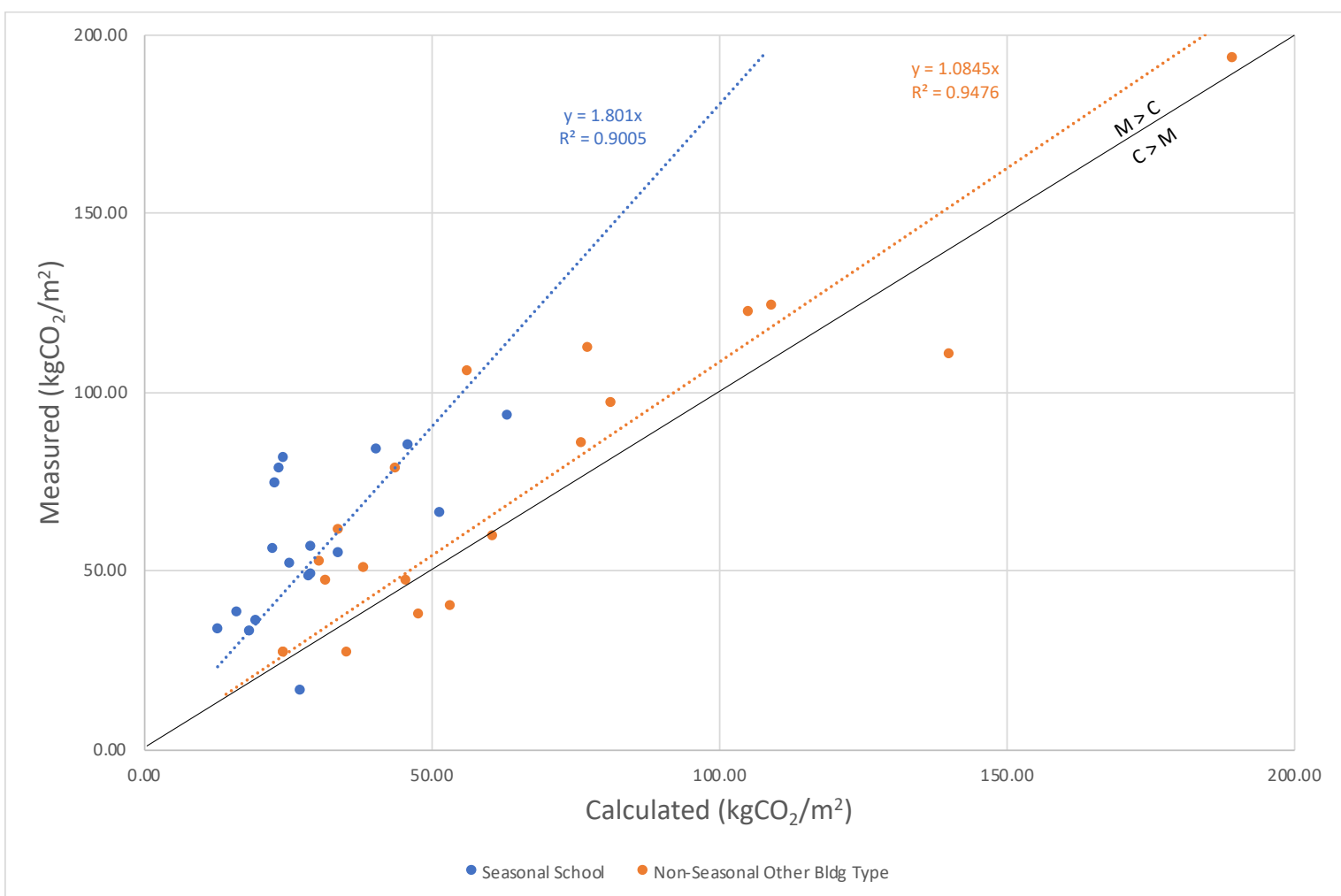

Figure 4.14 - Linear Regression comparing performance gaps of Seasonal vs Non-Seasonal Buildings

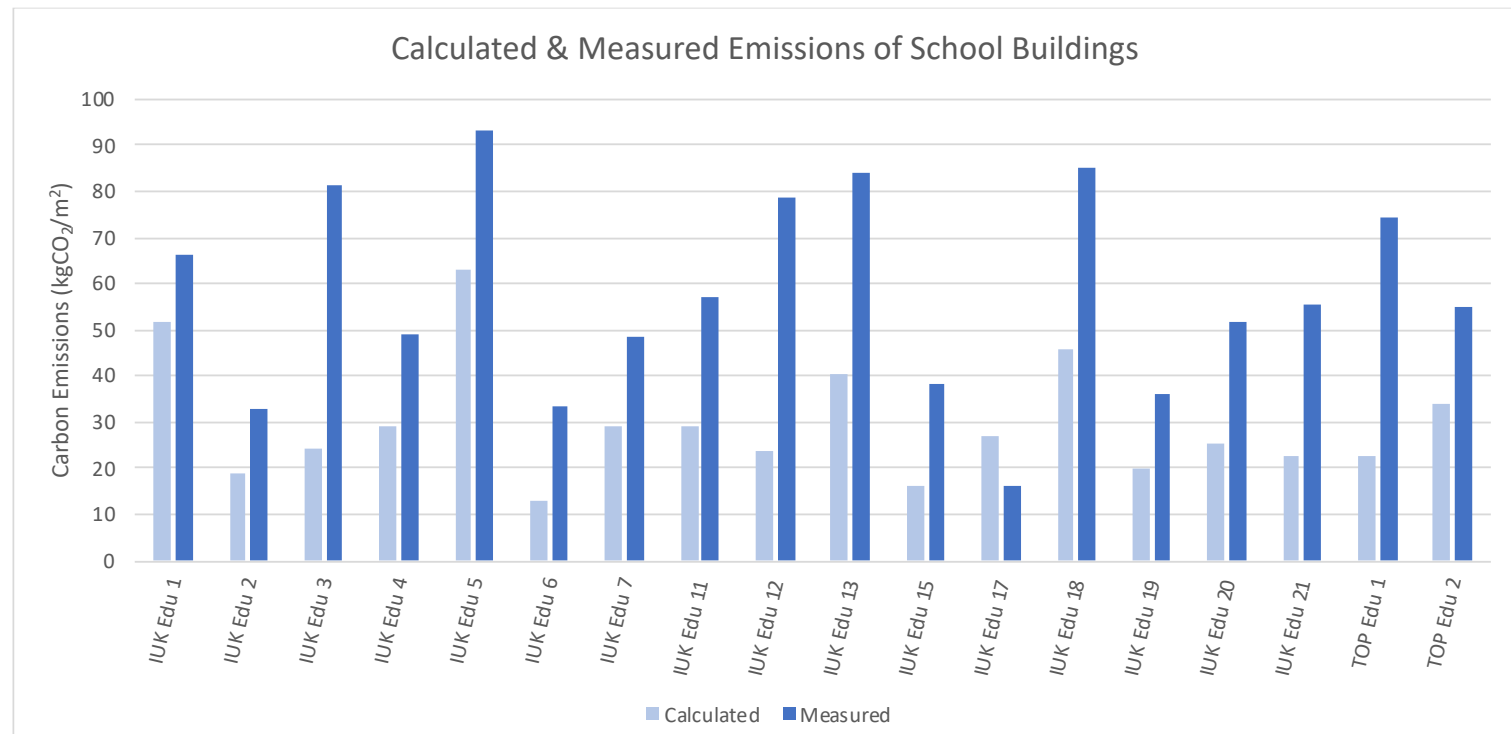

Figure 4.15 - Variance between calculated \& measured emissions in school buildings

\subsubsection{The combined effect of Ventilation Strategy \& Seasonality}

The performance discrepancy between seasonal and non-seasonal buildings becomes more significant when the ventilation strategy is considered in tandem. Mechanically ventilated school buildings perform worse than their non-seasonal, naturally ventilated counterparts both in terms of the difference between the mean performance gaps as seen in Figure 4.16 and also the mean performance against typical and good practice benchmarks. 


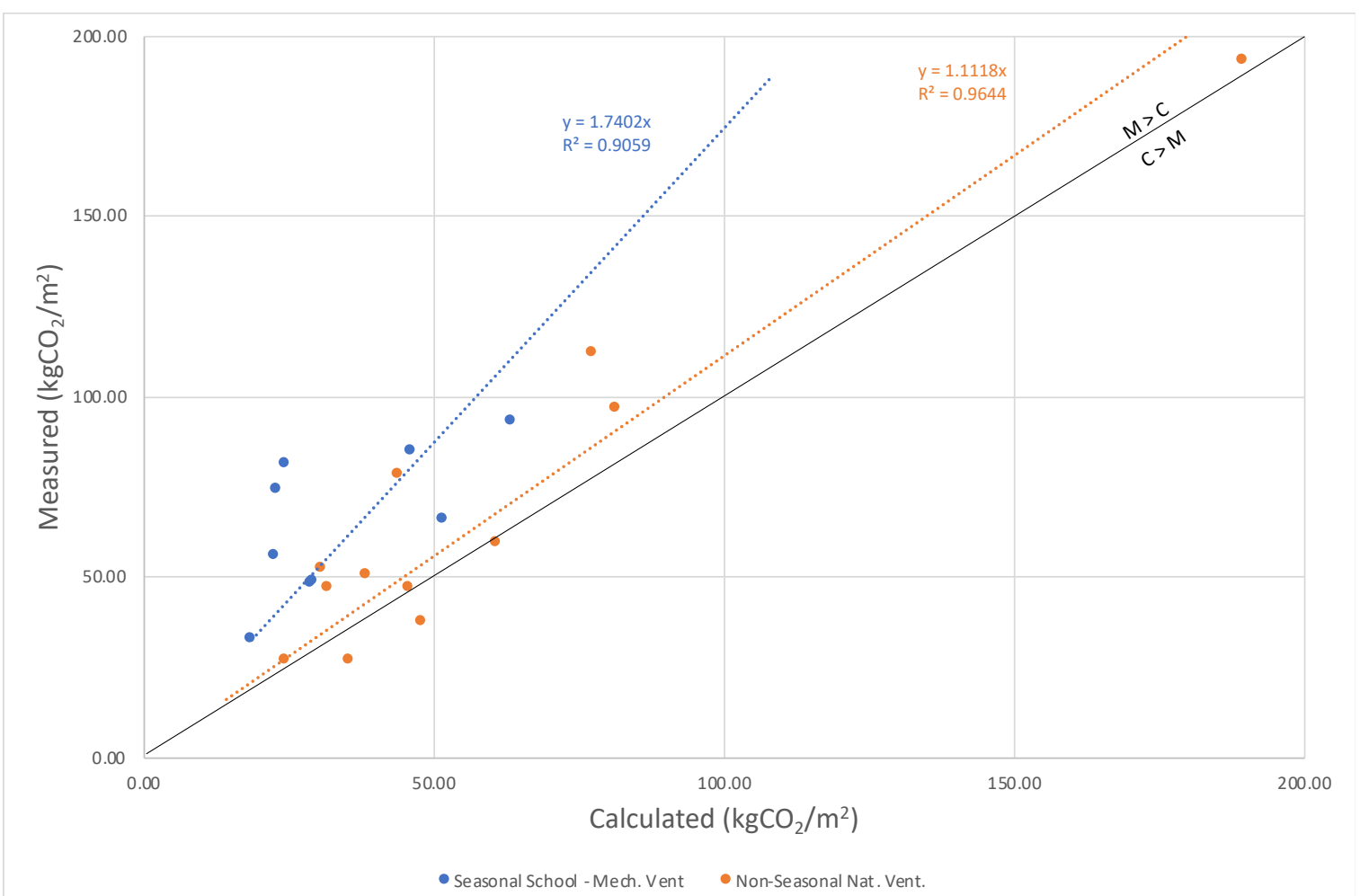

Figure 4.16 - Linear Regression comparing performance gaps of Mechanically Ventilated Schools vs Naturally Ventilated Non-Seasonal Buildings

\subsubsection{Additional Underlying Issues}

While other themes such as 'occupant behaviour' and 'system operation' were often mentioned in the BPE reports as issues related to the energy performance of a building and 'workmanship' and 'failure of low/zero carbon systems' were also indicated to be 'major' issues, no themes on their own had a strong direct correlation with the performance gap or the performance compared with the typical or good practice benchmark. Additionally, when all mentions of issues were summed, there was also no direct correlation with performance. This indicates that the frequency of mentions of an issue (or all issues) in the BPE reports is not directly correlated with energy performance. While difficult to quantify the impact of these underlying issues on their own, there is still a consensus in the literature and the BPE reports that they do impact the building performance.

\section{DISCUSSION}

The findings of the study clearly show that a one-size-fits-all approach is not adequate to untangle the intricate web of issues affecting the performance of buildings. A bespoke building needs a bespoke solution. However, there are useful lessons that may have wider applicability and are explored in this section.

\subsection{Reflection on Results and Analysis}

The complex entanglement of issues identified in this study presents a major challenge to the building industry of identifying specific problem areas and determining a straightforward, replicable and widely applicable solution to reduce the performance gap. 
When looking at the wider picture of issues established in the BPE reports, it would therefore be beneficial to determine if there is an approach that will address a majority of these interconnected issues and therefore, begin to 'untangle' the web. More disclosure of performance data and transparency of missteps in the industry could contribute to solving multiple established issues, such as lack of responsibility, workmanship, design and modelling errors, adequate submetering, better operation, and more incentives for stakeholder involvement throughout the process.

As many previous studies ${ }^{4,10,12,19}$ indicated, the need for a consistent approach to measuring performance and determining what 'good performance' means is crucial to both recognising the performance gap and increasing the disclosure of performance data. As $86 \%$ of the BPE studies indicated, adequate submetering is a problematic area that has a 'trickle-down' effect on system performance, management's ability to quickly respond to issues, and ultimately accountability. Adequate metering should not be seen as a solution to improve performance but rather as a pre-requisite.

Once adequate and accurate data is collected regarding building performance, it then needs to be compared to established performance targets to determine how well or poorly it is performing. However, there is still a lot of work and consensus needed to establish these performance indicators and metrics as stated by Bordass. ${ }^{46}$

In terms of the magnitude of the performance gap, the Innovate UK BPE and TOP properties seem to be on par with other research. The average performance gap error of $29 \%$ in this study compares with research by Van Dronkelaar, ${ }^{48}$ which found gaps of $\pm 34 \%$, and a previous thorough review of literature by Van Dronkelaar, ${ }^{10}$ which found errors between $16 \%$ and $67 \%$.

However, a high performance gap is not always an indicator of poor energy performance. For example, over half of the buildings that performed better than their typical and good practice benchmarks in this study had performance gap errors over 5\%. This may be indicative of either poor predictions of energy consumption or the need to update and revise benchmarking tools.

It is also important to note the difference in 'performance' when comparing energy use intensity $\left(\mathrm{kWh} / \mathrm{m}^{2}\right)$ to carbon emissions $\left(\mathrm{kgCO}_{2} / \mathrm{m}^{2}\right)$. When considering average performance across BPE \& TOP study properties, buildings seemed to perform better against the TM46 benchmark when looking specifically at electricity and fossil thermal energy intensity (29\% better) than emissions ( $8 \%$ better) despite the same energy consumption. This may be due to the consistent issues with the low/zero carbon systems installed. Out of 12 buildings in the study that installed biomass boilers, 8 of those reported major issues and most decommissioned those in favour of more carbon-intensive gas boilers. This would result in higher (worse) carbon emissions despite similar energy demand.

Most of the problems identified in the Innovate UK BPE study, which form part of the entangled web such as 'zero/low carbon failures' and 'measuring issues' are directly correlated with commissioning as shown earlier in Figure 4.10. The commissioning process can encompass many issues and the frequency of mentions in the reports (the highest number by far) may indicate that most projects struggle with commissioning to differing degrees even if their performance was not directly correlated. 
Commissioning has been found to have a ripple effect on other issues in previous studies. ${ }^{10,11,21}$ This finding was reinforced in this paper. The direct and indirect impact of commissioning can therefore be difficult to quantify despite the pervasiveness of the issue throughout most of the individual BPE studies. The inconsistent approaches to commissioning only add to the difficulty in calculating its impact. ${ }^{6}$

Consistently throughout the BPE reports, recommendations were made by the authors to make commissioning a part of the early planning stage of a building with efforts towards commissioning occurring throughout the design and construction phases and well after final completion.

Approaches such as Soft Landings seek to rectify some of the shortcomings of the standard commissioning process by implementing a graduated handover, extended aftercare and verification of performance through post-occupancy evaluations. ${ }^{21}$ The analysis of the Innovate UK BPE and TOP buildings did not identify a direct link between the use of Soft Landings and improved performance as seen in the T-test summary results in Table 5-1, which were not significant enough to reject the null hypothesis. However, only 5 of the 49 buildings followed the scheme and another 5 used a variation of parts of Soft Landings which is not a large enough sample to draw any distinct conclusions.

While commissioning is not a cure-all for inadequate design or installation errors, the consensus amongst the majority of BPE report authors seems to be the need to devote appropriate time and resources to commissioning, ensure the quality of the commissioning team is adequate for the complexity of the building, establish clear and measurable objectives, perform seasonal commissioning and ensure that data from commissioning is fed back to all stakeholders. 
Table 5-1 - Summary of T-Test Results for Researched Themes

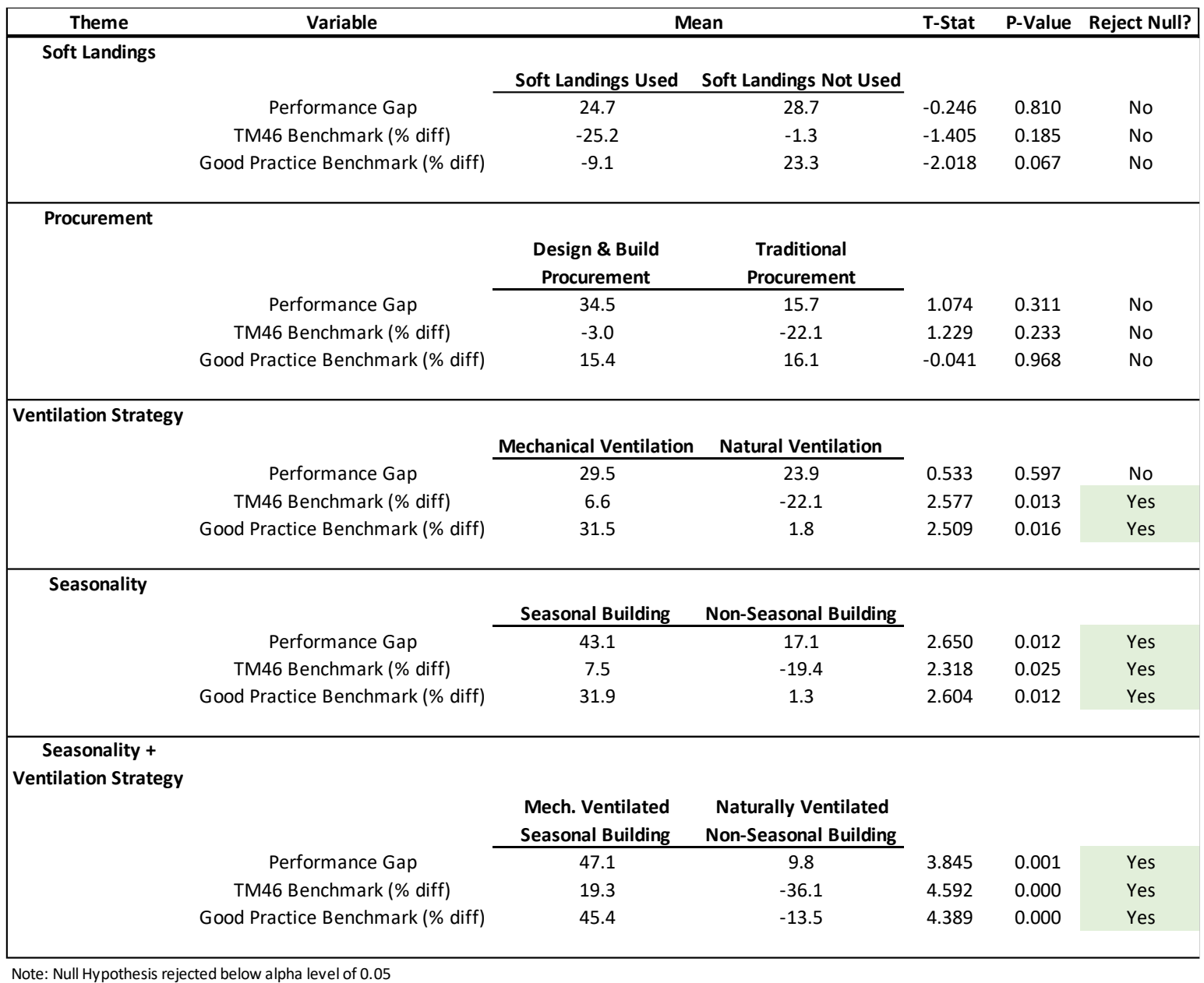

A natural ventilation strategy seemed to be the only controllable variable that resulted in a significantly different mean performance against the benchmarks, indicating higher risk of underperformance in mechanically ventilated buildings that are not managed well.

Seasonal operation was the only factor that was statistically significant and a key determinant of the performance gap in all T-Tests performed, highlighting the necessity of careful consideration and mitigation of risks at design stage and in operation such as detailed and refined control of building services strategy to cater for periods of partial occupancy effectively and efficiently.

The key question is how the issues that may cause a performance gap could be addressed given the bespoke nature of each project? There may be opportunities to use the procurement process to address a great deal of the major issues that plague building performance.

When procurement is viewed as an isolated issue, it is easy to dismiss its impact on the energy performance of a building. The analysis of the Innovate UK BPE reports did not find any direct correlation between procurement as an issue and energy consumption. Neither did the type of procurement indicate any conclusive impact on the measured performance gap. However, when used as a tool, procurement has the ability to stipulate methods to address a majority of issues that impact energy performance. It can establish energy performance targets for better disclosure and verification, mandate the scope and significance of 
commissioning, and designate accountable parties for monitoring and driving these goals and components throughout the process. It can encourage the level of stakeholder involvement from initial planning through handover and beyond, mandate the use of established tools such as Soft Landings and POEs, create a level of shared risk amongst all parties and better link the design process to operational performance by creating incentives to work towards common goals. In other words, it can be used to reward performance and not intentions.

\subsection{Research limitations and suggestion for future research}

While every effort was made to create robust and replicable research and analysis that can be applied to the larger building industry, there are some limitations to the scope of this paper and the data that was used.

The Innovate UK study summary report found that the scope and detail of the individual project BPE reports was often inconsistent and programme evaluators found that reliable information was difficult to obtain. ${ }^{7}$

While the individual report's authors followed a consistent structure, their commentary and analysis of the results and suggestions for improvement are subjective and vary based on their specific expertise and involvement with the projects. As the text of each BPE report reflects the individual author's focus, it may affect the qualitative analysis of this report if one issue is prioritized or mentioned more than others. For instance, since submetering data was required by the report's authors for each BPE analysis, and therefore important to their reporting, it may have been mentioned more frequently as an issue related to energy performance.

For a programme whose stated purpose was to address fundamental issues with building performance gaps, very few Innovate UK BPE reports actually calculated or stated the magnitude of this gap in the subject buildings and few contained straightforward design-stage energy predictions needed to make these calculations. This was likely due to the lack of available design data for the BPE authors' analysis. Instead, there was a focus on the regulated energy predictions included in EPCs, as this information was available for all BPE buildings, which had been completed recently. The EPC results cannot accurately be directly compared with in-use data without complicated extraction of underlying submitted data. ${ }^{49}$

(See further description of how this paper addressed this issue for its own data analysis in the previous section: Establishing the magnitude of the performance gap.)

There was also no specific requirement for BPE projects to follow a robust and standardised process to evaluate building fabric performance in-use. Building fabric $U$ values assumed at design stage are not necessarily reflective of the actual $U$ values; details such as repeating and non-repeating thermal bridges and insulation details are often not fully captured at design stage. The pressure tests carried out after construction to determine the air permeability of building fabric are also not necessarily indicative of long-term performance. It is, therefore, important to thoroughly cover fabric performance in a holistic building performance evaluation.

The client and designers in the TOP office building attempted to set out and achieve operational energy performance targets, following the lessons learned from the Innovate UK BPE programme. This was facilitated by an energy performance contract and designed for a specific user (i.e. owner occupier). This building is among the top performers in the sample 
of buildings investigated in this study. Targeting operational performance at design stage and setting up the appropriate contractual arrangements and systems of incentives to achieve these targets in practice along with the costs and benefits of these projects should be the subject of a future study as well as the impact of designing for a speculative or known occupier on the in-use performance of a building.

While specific design margins were not available for analysis in this paper, the tendency to oversize plant capacity, beyond justified margins, may contribute to inefficiencies in energy performance and should be further evaluated, potentially through the NABERS UK Design for Performance initiative and its encouragement of detailed HVAC modelling at design stages.

\section{Conclusion}

While the performance gap is not a new issue, and some uncertainty in performance is inevitable, the current chasm between design predictions and measured energy consumption still plagues the progress towards significant reductions in greenhouse gas emissions in the building sector.

This paper aimed to identify inherent risks in the building process that contributed to the performance gap and sought to answer whether a practical solution or method could address most of the issues.

The issues and processes that affect the performance gap are often intangible and difficult to directly quantify. This paper echoed other research, which found that an interconnected web of issues, with complex interdependencies, contributes to the performance gap more than a single, stand-out issue.

The multitude of the variables involved presents a formidable challenge in finding practical solutions. However, the results indicate that the combination of the ventilation strategy of a building and the building services control strategy during partial occupancy is a key determinant of the performance gap. It is therefore essential to identify potential risks associated with the ventilation strategy of a building and specify detailed and refined control strategies responsive to partial occupancy (e.g. effective demand-controlled ventilation, refine zoning for automated lighting control, hydraulic isolation of un-occupied zones for heating and cooling, power-down management of IT systems).

Given the complexity of building procurement process and several potential risks involved, a more holistic solution with an ability to transcend all stages of the building process is needed to address the complexity and concatenation of the problems. A more straightforward procurement approach with clearly delineated performance targets and responsibilities along with thorough and collaborative commissioning, which is instituted at the project start, managed throughout and extended beyond initial handover, are concrete steps that can address many of the underlying issues affecting poor building performance. When combined with regulation, such as mandated performance data disclosure, or an appropriate system of incentives to facilitate transparency in energy performance data and contributing factors, many problems afflicting this industry could be addressed. 


\section{ACKNOWLEDGEMENT}

This study was supported by the EPSRC through the 'Total Operational Performance of Low Carbon Buildings in China and the UK (TOP)' project (EPSRC Grant number $\mathrm{EP} / \mathrm{N} 009703 / 1)$. 


\section{REFERENCES}

1. IEA. Tracking Buildings 2020. Paris: International Energy Agency, https://www.iea.org/reports/trackingbuildings-2020 (2020).

2. UN Environment Programme, IEA. 2019 global status report for buildings and construction: Towards a zero-emission, efficient and resilient buildings and construction sector. Global Alliance for Buildings and Construction, 2019.

3. CIBSE. TM61: Operational performance of buildings. Chartered Institution of Building Services Engineers, 2020.

4. de Wilde P. The gap between predicted and measured energy performance of buildings: A framework for investigation. Autom Constr 2014; 41: 40-49.

5. Bunn R, Burman E. S-Curves to Model and Visualise the Energy Performance Gap between Design and Reality - first steps to a practical tool. CIBSE Tech Symp 2015; 18.

6. $\quad$ de Wilde P. Building performance analysis. Wiley Blackwell, 2018.

7. Palmer J, Terry N, Armitage P. Building Performance Evaluation Programme: Findings from non-domestic projects. Innovate UK, https://assets.publishing.service.gov.uk/government/uploads/system/uploads/attachment_data/file/497761/ Non-Domestic_Building_performance_full_report_2016.pdf (January 2016).

8. Williamson JB. The Gap Between Design and Build. Scott ENERGY Cent Edinb NAPIER Univ 2012; 23.

9. DCLG. APPROVED DOCUMENT L2A: conservation of fuel and power in new buildings other than dwellings, ... 2013 edition with 2016 amendments. NBS RIBA ENTERPRISES, 2016.

10. van Dronkelaar C, Dowson M, Spataru C, et al. A Review of the Regulatory Energy Performance Gap and Its Underlying Causes in Non-domestic Buildings. Front Mech Eng; 1. Epub ahead of print 13 January 2016. DOI: $10.3389 /$ fmech.2015.00017.

11. Morant M. The Performance Gap - Non Domestic Buildings. Report CEW1005, Cardiff: AECOM/Constructing Excellence Wales, 2012.

12. Cohen DR, Ratcliffe S, Bannister P. Design for Performance: development of a national UK scheme. CIBSE Tech Symp 2019; 16.

13. Newsham GR, Mancini S, Birt BJ. Do LEED-certified buildings save energy? Yes, but.... Energy Build 2009; 41: 897-905.

14. Menezes AC, Cripps A, Bouchlaghem D, et al. Predicted vs. actual energy performance of non-domestic buildings: Using post-occupancy evaluation data to reduce the performance gap. Appl Energy 2012; 97: $355-364$.

15. Jain N, Burman E, Robertson C, et al. Building performance evaluation: Balancing energy and indoor environmental quality in a UK school building. Build Serv Eng Res Technol 2020; 41: 343-360.

16. Korjenic A, Bednar T. Validation and evaluation of total energy use in office buildings: A case study. Autom Constr 2012; 23: 64-70.

17. Love J, Wingfield J, Smith AZP, et al. Hitting the target and missing the point': Analysis of air permeability data for new UK dwellings and what it reveals about the testing procedure. Energy Build 2017; 155: 8897. 
18. ZCH. SUMMARY: THE PERFORMANCE GAP - END OF TERM REPORT: A summary of the Zero Carbon Hub's End of Term report on Closing the Gap between Design and As-Built Performance. Zero Carbon Hub, www.zerocarbonhub.org (July 2014).

19. ZCH. Carbon Compliance for Tomorrow's New Homes: A Review of the Modelling Tool and Assumptions Overview of Findings and Recommendations. London: Zero Carbon Hub, www.zerocarbonhub.org (July 2010).

20. Latham M. Constructing the team: final report: joint review of procurement and contractual arrangements in the United Kingdom construction industry. London: HMSO, 1994.

21. Bunn R, Way M. Soft Landings. Bracknell: Building Services Research and Information Association and Usable Building Trust, 2010.

22. Wang L, Mathew P, Pang X. Uncertainties in energy consumption introduced by building operations and weather for a medium-size office building. Energy Build 2012; 53: 152-158.

23. Harputugil, de Wilde. The interaction between humans and buildings for energy efficiency: A critical review. Energy Res Soc Sci; 71. Epub ahead of print January 2021. DOI: https://doi.org/10.1016/j.erss.2020.101828.

24. CIBSE. Energy assessment and reporting method. TM22. London: Chartered Institution of Building Services Engineers, http://app.knovel.com/hotlink/toc/id:kpEARMCIBM/energy-assessment-and (2006, accessed 6 June 2020).

25. Cohen R, Bordass B. Mandating transparency about building energy performance in use. Build Res Inf 2015; 43: 534-552.

26. Turner C, Frankel M. Energy Performance of LEED® for New Construction Buildings. White Salmon, Washington: New Buildings Institute, 4 March 2008.

27. Lim M, Law S, Wilson A. Understanding the numbers behind the NABERS Energy rating system. Sheffield, UK: CIBSE, 2019, p. 12.

28. Tuomela-Pyykkönen M, Aaltonen K, Haapasalo H. Procurement in the Real Estate and Construction Sector (RECS) - Preliminary Context-specific Attributes. Procedia Econ Finance 2015; 21: 264-270.

29. NABERS. The Key Principles and Defining Features of NABERS. Sydney: Common Capital Pty Ltd for the Office of Environment and Heritage, https://www.nabers.gov.au/about/what-nabers (September 2014).

30. GLA. Implementing the London Plan 'be seen' energy monitoring requirement. ADD2352, London: Greater London Authority, 15 July 2019.

31. Usable Buildings Trust. Usable Buildings https://www.usablebuildings.co.uk/UsableBuildings/BPENonDomesticSortedByProjectReferenceListAll. html (2020, accessed 11 December 2020).

32. Shrubsole C, Hamilton IG, Zimmermann N, et al. Bridging the gap: The need for a systems thinking approach in understanding and addressing energy and environmental performance in buildings. Indoor Built Environ 2019; 28: 100-117.

33. CIBSE. TM62: Operational performance: Surveying occupant satisfaction. Chartered Institution of Building Services Engineers, 2020.

34. CIBSE. TM63: Operational performance: Building performance modelling and calibration for evaluation of energy in-use. Chartered Institution of Building Services Engineers, 2020.

35. CIBSE. TM64: Operational performance: Indoor air quality-emissions sources and mitigation measures. Chartered Institution of Building Services Engineers, 2020. 
36. UKCIP, CIBSE, Arup, et al. Weather Data.

37. Stark. Degree Days for Free: Powered by Stark. Degree Days for Free: Powered by Stark, https://poweredby.stark.co.uk/SEO/SEO.aspx (2020, accessed 26 August 2020).

38. CIBSE. Energy benchmarks - CIBSE TM46: 2008. London: Chartered Institution of Building Services Engineers,

http://VH7QX3XE2P.search.serialssolutions.com/?V=1.0\&L=VH7QX3XE2P\&S=AC_T_B\&C=Energy

\%20Benchmarks\%20-\%20CIBSE\%20TM46:\%202008\&T=marc\&tab=BOOKS $\quad(2008, \quad$ accessed 10 August 2020).

39. AECOM, University of Exeter, University of Bath. Estover Community College - Building Performance Evaluation. 450026, Innovate UK, 30 July 2014.

40. Hong SM. Benchmarking the energy performance of the UK non-domestic stock: a schools case study. $\mathrm{PhD}$ Thesis, University College London, 2015.

41. CIBSE. Energy Benchmarking Tool Dashboard, https://www.cibse.org/Knowledge/Benchmarking (2020, accessed 19 December 2020).

42. CIBSE. Energy efficiency in buildings: CIBSE Guide F. Chartered Institution of Building Services Engineers, http://app.knovel.com/web/toc.v/cid:kpCIBSEGF7/viewerType:toc/root_slug:cibse-guide-fenergy (2012, accessed 21 August 2020).

43. Saldaña J. The coding manual for qualitative researchers. 3E [Third edition]. Los Angeles ; London: SAGE, 2016.

44. Braun V, Clarke V. Using thematic analysis in psychology. Qual Res Psychol 2006; 3: 77-101.

45. Studio Partington. Greenfields Community Housing Headquarters - Building Performance Evaluation. BPE 450007, Innovate UK, 21 November 2014.

46. Bordass B. Metrics for energy performance in operation: the fallacy of single indicators. Build Cities 2020; 1: 260-276.

47. Burman E, Kimpian J, Mumovic D. Building Schools for the Future: Lessons Learned From Performance Evaluations of Five Secondary Schools and Academies in England. Front Built Environ 2018; 4: 22.

48. van Dronkelaar C, Dowson M, Spataru C, et al. Quantifying the Underlying Causes of a Discrepancy Between Predicted and Measured Energy Use. Front Mech Eng 2019; 5: 20.

49. BBP. MINIMUM ENERGY EFFICIENCY STANDARDS AND HERITAGE PROPERTIES: Mitigating risks through the procurement and interpretation of Energy Performance Certificates. Better Buildings Partnership,

https://www.betterbuildingspartnership.co.uk/sites/default/files/media/attachment/BBP_Heritage\%20EPC _Insight.pdf (May 2018). 


\section{APPENDIX A: BPE \& TOP PROPERTY DATA}

\begin{tabular}{|c|c|c|c|c|c|c|c|c|}
\hline Report Ref\# & Property Name & $\begin{array}{l}\text { Climate Zone } \\
\text { (CIBSE TM46) }\end{array}$ & Sector & $\begin{array}{c}\text { Total Useful } \\
\text { Floor Area } \\
\left(\mathrm{m}^{2}\right)\end{array}$ & $\begin{array}{l}\text { Procurement } \\
\text { Route }\end{array}$ & BREEAM Rating & $\begin{array}{c}\text { Main } \\
\text { Heating Fuel }\end{array}$ & Ventilation \\
\hline 450048 & IUK Public 1 & 3 & Public Service & 563 & Design \& Build & Outstanding & Grid Elec & Natural \\
\hline 450060 & IUK Retail 1 & 6 & Retail & 6,293 & Design \& Build & Very good & Natural Gas & Natural \\
\hline 45002 & IUK Edu 1 & 5 & Education & 5,630 & Design \& Build & Excellent & Natural Gas & Mechanical \\
\hline 45002 & IUK Hotel 1 & 5 & Hotel/other residential & 9,250 & Design \& Build & Excellent & Natural Gas & Natural \\
\hline 450063 & IUK Hotel 2 & 1 & Hotel/other residential & 3,617 & $n / a$ & Good & Natural Gas & Mechanical \\
\hline 450063 & IUK Office 1 & 1 & Office & 3,206 & $n / a$ & Good & Natural Gas & Mechanical \\
\hline 45001 & IUK Edu 2 & 1 & Education & 685 & Traditional & Very Good & Natural Gas & Mechanical \\
\hline 450075 & IUK Health 1 & 12 & Health & 2,649 & Design \& Build & Excellent & Grid Elec & Mixed Mode \\
\hline 450113 & IUK Office 2 & 3 & Office & 4,258 & Traditional & Excellent & Natural Gas & Natural \\
\hline 450030 & IUK Edu 3 & 2 & Education & 10,588 & Design \& Build & Excellent & Biomass & Mechanical \\
\hline 450004 & IUK Edu 4 & 7 & Education & 2,969 & Design \& Build & Very Good & Natural Gas & Mechanical \\
\hline 450035 & IUK Edu 5 & 1 & Education & 302 & Traditional & Very good & Natural Gas & Mechanical \\
\hline 450035 & IUK Edu 6 & 1 & Education & 817 & Traditional & Very good & Natural Gas & Natural \\
\hline 450114 & IUK Culture 1 & 1 & Culture & 362 & $n / a$ & - & Grid Elec & Natural \\
\hline 450003 & IUK Public 2 & 2 & Public Service & 4,468 & Design \& Build & Very good & Biomass & Mechanical \\
\hline 450006 & IUK Office 3 & 6 & Office & 705 & Traditional & Very good & Natural Gas & Natural \\
\hline 450047 & IUK Edu 7 & 1 & Education & 11,624 & Design \& Build & Very good & Biomass & Mechanical \\
\hline 450032 & IUK Edu 8 & 4 & Education & 1,990 & Traditional & Excellent & Natural Gas & Mechanical \\
\hline 450058 & IUK Office 4 & 1 & Office & 2,150 & Traditional & - & Grid Elec & Mechanical \\
\hline 450026 & IUK Edu 9 & 4 & Education & 16,900 & Design \& Build & Very Good & Biomass & Natural \\
\hline 450087 & IUK Office 5 & 17 & Office & 3,107 & Design \& Build & Excellent & Biomass/Oil & Natural \\
\hline 450007 & IUK Office 6 & 12 & Office & 2,180 & Traditional & Very good & Grid Elec & Mechanical \\
\hline 450033 & IUK Office 7 & 6 & Office & 4,024 & Design \& Build & Excellent & Grid Elec & Natural \\
\hline 450059 & IUK Edu 10 & 2 & Education & 2,492 & Design \& Build & - & Natural Gas & Natural \\
\hline 450004 & IUK Edu 11 & 1 & Education & 14,610 & Design \& Build & Excellent & Grid Elec & Natural \\
\hline 450109 & IUK Retail 2 & 7 & Retail & 19,401 & Traditional & Excellent & Biomass & Mechanical \\
\hline 450041 & IUK Public 3 & 1 & Public Service & 800 & Traditional & Passive House & Grid Elec & Mechanical \\
\hline 450090 & IUK Indust. 1 & 5 & Industrial & 8,413 & Design \& Build & - & Natural Gas & Mechanical \\
\hline 450111 & IUK Health 2 & 5 & Health & 2,538 & Design \& Build & Excellent & Natural Gas & Natural \\
\hline 450044 & IUK Edu 12 & 6 & Education & 2,600 & Design \& Build & - & Natural Gas & Natural \\
\hline 450088 & IUK Office 8 & 14 & Office & 1,450 & Traditional & - & Natural Gas & Mechanical \\
\hline 450008 & IUK Edu 13 & 10 & Education & 10,172 & Design \& Build & Very Good & Biomass & Natural \\
\hline 450008 & IUK Edu 14 & 1 & Education & 10,490 & Design \& Build & Very Good & Natural Gas & Mechanical \\
\hline 450115 & IUK Culture 2 & 2 & Culture & 370 & Design \& Innovation & - & Grid Elec & Mechanical \\
\hline 450043 & IUK Office 9 & 4 & Office & 3,747 & Design \& Build & Excellent & Biomass & Natural \\
\hline 450084 & IUK Hotel 3 & 2 & Hotel/other residential & 2,799 & $n / a$ & Excellent & Natural Gas & Mechanical \\
\hline 450042 & IUK Edu 15 & 5 & Education & 1,660 & Design \& Build & Excellent & Natural Gas & Natural \\
\hline 450112 & IUK Hotel 4 & 1 & Hotel/other residential & 6,000 & Design \& Build & Excellent & Natural Gas & Mechanical \\
\hline 450045 & IUK Edu 16 & 13 & Education & 16,185 & Design \& Build & Very Good & Natural Gas & Natural \\
\hline 450064 & IUK Edu 17 & 6 & Education & 1,120 & Traditional & Excellent & Biomass & Natural \\
\hline 450008 & IUK Edu 18 & 7 & Education & 10,496 & Traditional & Very good & Natural Gas & Mechanical \\
\hline 450062 & IUK Edu 19 & 1 & Education & 2,916 & $n / a$ & Excellent & Biomass & Natural \\
\hline 450030 & IUK Edu 20 & 2 & Education & 8,250 & $\mathrm{n} / \mathrm{a}$ & - & Natural Gas & Mixed Mode \\
\hline 450092 & IUK Public 4 & 5 & Public Service & 982 & Design \& Build & Excellent & Natural Gas & Natural \\
\hline 450057 & IUK Edu 21 & 12 & Education & 4,300 & $n / a$ & Excellent & Biomass & Mechanical \\
\hline 450043 & IUK Office 10 & 4 & Office & 800 & Design \& Build & Passive House & Biomass & Natural \\
\hline 450089 & IUK Edu 22 & 13 & Education & 17,835 & $n / a$ & 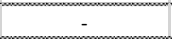 & Biofuel & Mechanical \\
\hline 450111 & IUK Health 3 & 5 & Health & 2,522 & Design \& Build & Excellent & Natural Gas & Natural \\
\hline 450028 & IUK Office 11 & 11 & Office & 2,514 & $n / a$ & - & Natural Gas & Natural \\
\hline TOP & TOP Health 1 & 7 & Health & 5,317 & Design \& Build & Very good & Natural Gas & Mechanical \\
\hline TOP & TOP Health 2 & 5 & Health & 14,726 & Design \& Build & Very good & Natural Gas & Mechanical \\
\hline TOP & TOP Edu 1 & 1 & Education & 21,405 & Design \& Build & Very good & Natural Gas & Mechanical \\
\hline TOP & TOP Edu 2 & 1 & Education & 11,620 & Design \& Build & Excellent & Natural Gas & Natural \\
\hline TOP & TOP Office 1 & 5 & Office & 7,024 & Design \& Build & - & Natural Gas & Natural \\
\hline
\end{tabular}




\section{APPENDIX B: FREQUENCY OF QUALITATIVE CODED THEMES FOR EACH REPORT}

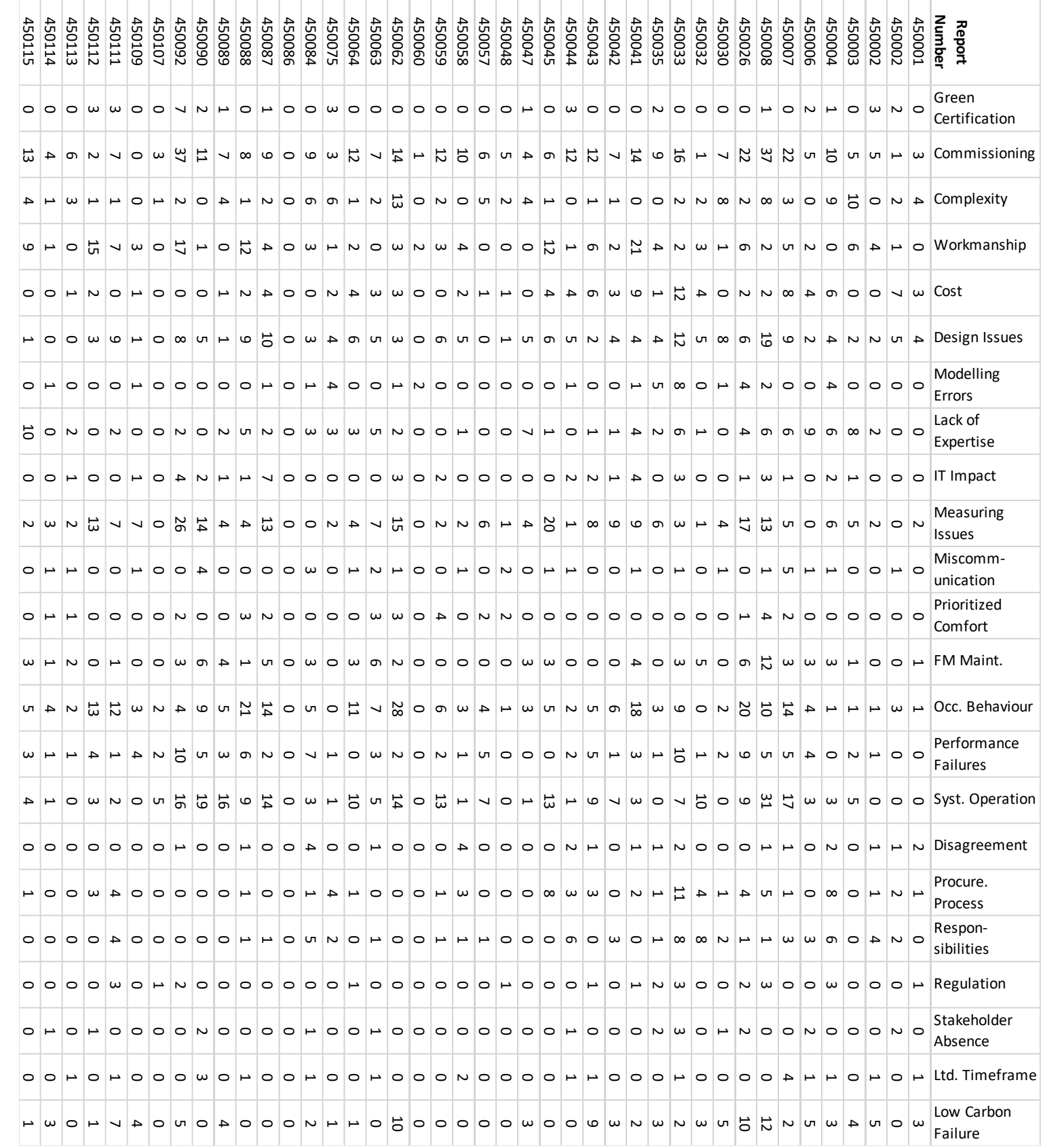

